\title{
Theta Bursts Precede, and Spindles Follow, Cortical and Thalamic Downstates in Human NREM Sleep
}

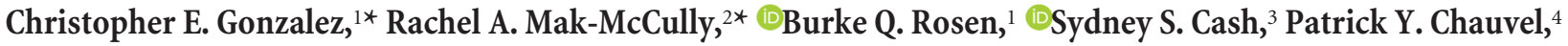 \\ Hélène Bastuji, ${ }^{5}$ Marc Rey, ${ }_{4}^{4}$ and Eric Halgren ${ }^{6}$ \\ ${ }^{1}$ Department of Neurosciences, University of California San Diego, La Jolla, California 92093, 22University California Berkeley, Berkeley, California 94720 , \\ ${ }^{3}$ Department of Neurology, Massachusetts General Hospital and Harvard Medical School, Harvard University, Boston, Massachusetts 02114, ${ }^{4}$ Aix-Marseille \\ Université, Marseille 13385, France, ${ }^{5}$ Central Integration of Pain, Lyon Neuroscience Research Center, INSERM, U1028, CNRS, UMR5292, Université \\ Claude Bernard, Lyon, Bron, France, and ${ }^{\circ}$ Departments of Radiology and Neurosciences, University of California, San Diego, California 92093
}

Since their discovery, slow oscillations have been observed to group spindles during non-REM sleep. Previous studies assert that the slow-oscillation downstate (DS) is preceded by slow spindles $(10-12 \mathrm{~Hz})$ and followed by fast spindles $(12-16 \mathrm{~Hz})$. Here, using both direct transcortical recordings in patients with intractable epilepsy ( $n=10,8$ female), as well as scalp EEG recordings from a healthy cohort $(n=3,1$ female), we find in multiple cortical areas that both slow and fast spindles follow the DS. Although discrete oscillations do precede DSs, they are theta bursts (TBs) centered at 5- $8 \mathrm{~Hz}$. TBs were more pronounced for DSs in NREM stage 2 (N2) sleep compared with N3. TB with similar properties occur in the thalamus, but unlike spindles they have no clear temporal relationship with cortical TB. These differences in corticothalamic dynamics, as well as differences between spindles and theta in coupling high-frequency content, are consistent with NREM theta having separate generative mechanisms from spindles. The final inhibitory cycle of the TB coincides with the DS peak, suggesting that in N2, TB may help trigger the DS. Since the transition to N1 is marked by the appearance of theta, and the transition to N2 by the appearance of DS and thus spindles, a role of TB in triggering DS could help explain the sequence of electrophysiological events characterizing sleep. Finally, the coordinated appearance of spindles and DSs are implicated in memory consolidation processes, and the current findings redefine their temporal coupling with theta during NREM sleep.

Key words: corticothalamic; downstates; iEEG; sleep; spindles; theta

\section{Significance Statement}

Sleep is characterized by large slow waves which modulate brain activity. Prominent among these are downstates (DSs), periods of a few tenths of a second when most cells stop firing, and spindles, oscillations at $\sim 12$ times a second lasting for $\sim$ a second. In this study, we provide the first detailed description of another kind of sleep wave: theta bursts (TBs), a brief oscillation at $\sim$ six cycles per second. We show, recording during natural sleep directly from the human cortex and thalamus, as well as on the scalp, that TBs precede, and spindles follow DSs. TBs may help trigger DSs in some circumstances, and could organize cortical and thalamic activity so that memories can be consolidated during sleep.

\section{Introduction}

During NREM sleep, the brain endogenously produces electrical activity dominated by larger amplitude, lower frequency $(0.1-16$

Received Feb. 20, 2018; revised Aug. 10, 2018; accepted Aug. 28, 2018.

Author contributions:C.E.G. and R.A.M.-M. wrote the first draft of the paper; C.E.G., R.A.M.-M.,S.S.C.,P.Y.C., H.B., M.R., and E.H. edited the paper; C.E.G., R.A.M.-M., and E.H. designed research;C.E.G., R.A.M.-M., B.Q.R.,P.Y.C., H.B., and M.R. performed research; S.S.C., P.Y.C., H.B., and M.R. contributed unpublished reagents/analytic tools; C.E.G., R.A.M.-M., and B.Q.R. analyzed data; C.E.G. and R.A.M.-M. wrote the paper.

This work was supported by the National Institutes of Health (Grants R01-MH-099645 and R01-EB-009282), the U.S. Office of Naval Research (Grant N00014-13-1-0672), the National Science Foundation Graduate Research Fellowships Program, and the National Institute of Mental Health-NIH (T32 Cognitive Neuroscience Training Grant). We thank Nima Dehghani for EEG data, Donald Hagler for spindle detection scripts, Fabrice Bartolomei for access to data and analysis input, Catherine Liegeois-Chauvel for research access, and Jean Regis for electrode localization for the Marseille patient.
$\mathrm{Hz}$ ) rhythms compared with wake or REM states. Downstates (DSs) (periods of neuronal quiescence lasting a few hundred milliseconds) and sleep spindles ( $\sim 0.5-2 \mathrm{~s}, 10-16 \mathrm{~Hz}$ oscillations) are two canonical NREM events with initiating mechanisms largely attributed to cortical and thalamic activities, respectively. However, the extensive bidirectional connections between cortex and thalamus precludes a simple entraining mechanism for ei-

The authors declare no competing financial interests.

${ }^{*}$ C.E.G. and R.A.M.-M. contributed equally to this work.

Correspondence should be addressed to Christopher E. Gonzalez, Department of Neurosciences Graduate Program, University of California, 9500 Gilman Drive 0634, La Jolla, CA 92093. E-mail: cegonzalez@ucsd.edu.

https://doi.org/10.1523/JNEUROSCI.0476-18.2018

Copyright $\odot 2018$ the authors $\quad 0270-6474 / 18 / 389989-13 \$ 15.00 / 0$ 
Table 1. Demographic and clinical information

\begin{tabular}{|c|c|c|c|c|c|c|c|}
\hline Patient & Sex & Age & Handedness & Clinical diagnosis & Pathological diagnosis & Imaging & Focus \\
\hline 1 & M & 35 & - & Right temporal lobe epilepsy & No pathology obtained & Normal & $\begin{array}{l}\text { Temporo-parieto-occipi- } \\
\text { tal junction }\end{array}$ \\
\hline 2 & $\mathrm{~F}$ & 37 & $\mathrm{R}$ & Temporal lobe epilepsy & No pathology obtained & Normal & Hippocampus \\
\hline 3 & M & 45 & L & CPS; bitemporal & No pathology obtained & - & $\begin{array}{l}\text { Left and right mesial } \\
\text { temporal lobes }\end{array}$ \\
\hline 4 & $\mathrm{~F}$ & 45 & $\mathrm{R}$ & CPS; multifocal & $\begin{array}{l}\text { Multifocal: temporal, parietal, } \\
\text { occipital }\end{array}$ & - & Temporal \\
\hline 5 & $\mathrm{~F}$ & 65 & $\mathrm{R}$ & $\begin{array}{l}\text { CPS; temporal lobe epilepsy with two foci: } \\
\text { left mesial temporal structures and } \\
\text { right subfrontal region }\end{array}$ & No pathology obtained & - & $\begin{array}{r}\text { Right subfrontal and } \\
\text { anterior temporal }\end{array}$ \\
\hline 6 & $\mathrm{~F}$ & 32 & R & Left temporal lobe epilepsy & Nonspecific gliosis & Normal & $\begin{array}{l}\text { Hippocampus, entorhinal } \\
\text { cortex, amygdala }\end{array}$ \\
\hline 7 & $\mathrm{~F}$ & 23 & $\mathrm{R}$ & Right temporal lobe epilepsy & Type I focal dysplasia & Normal & $\begin{array}{l}\text { Hippocampus, entorhinal } \\
\text { cortex, anterior insula }\end{array}$ \\
\hline 8 & $\mathrm{~F}$ & 28 & $\mathrm{R}$ & Right temporal occipital epilepsy & Type II focal dysplasia & $\begin{array}{l}\text { Focal cortical dysplasia in } \\
\text { right fusiform }\end{array}$ & $\begin{array}{l}\text { Fusiform gyrus, entorhi- } \\
\text { nal cortex }\end{array}$ \\
\hline 9 & $\mathrm{~F}$ & 50 & $\mathrm{R}$ & Right temporal occipital epilepsy & No pathology obtained & Normal & Right fusiform gyrus \\
\hline 10 & $\mathrm{~F}$ & 27 & $\mathrm{R}$ & Right temporal lobe epilepsy & No pathology obtained & Right hippocampal sclerosis & $\begin{array}{l}\text { Hippocampus, entorhinal } \\
\text { cortex, amygdala }\end{array}$ \\
\hline
\end{tabular}

CPS, Complex partial seizures.

ther event and properties such as duration (Bazhenov et al., 2002; Bonjean et al., 2011; Barthó et al., 2014), frequency of occurrence (Timofeev et al., 2000), and synchrony (Contreras et al., 1996) are all shaped by their cooperative dynamics (Steriade, 1997; Crunelli and Hughes, 2010). These rhythms are believed to serve functional roles in sleep-dependent memory consolidation (Sejnowski and Destexhe, 2000; Diekelmann and Born, 2010; Hanert et al., 2017). In particular, the specific grouping of spindles by slow waves has been associated with improved declarative memory in humans (Mölle et al., 2011; Niknazar et al., 2015) and fear conditioning in mice (Latchoumane et al., 2017).

Although several studies report faster spindle frequency activity $(>12 \mathrm{~Hz})$ occurs on the transition from the down to upstate (US) (Andrillon et al., 2011; Mölle et al., 2011; Cox et al., 2014a; Klinzing et al., 2016), the temporal relation of lower frequency (4-12 Hz) content to DSs has not been definitively established. This relationship is more clear during NREM stage 2 (N2) sleep, when DSs usually occur without preceding USs as the main component of the K-complex (KC) (Cash et al., 2009; Mak-McCully et al., 2015). Some investigators have observed "polyphasic waves [... ] just before the onset of the negative K-complex sharp wave" (Rodenbeck et al., 2006) or an $\sim 7 \mathrm{~Hz}$ short-lasting "intra-KC" oscillation (Kokkinos and Kostopoulos, 2011; Kokkinos et al., 2013). More recently, however, the US to DS transition has been associated with slow spindle activity (9-12 Hz) (Mölle et al., 2011; Klinzing et al., 2016; Yordanova et al., 2017). Findings from the latter studies bolster the hypothesis that there are distinct types of spindles, slow and fast, which could have their own rhythmogenesis mechanisms (Timofeev and Chauvette, 2013; Fogerson and Huguenard, 2016). Here, we present findings that challenge this hypothesis using bipolar transcortical and thalamic recordings from epileptic patients to obtain focal measures of DSs and spindles. We confirm these findings at the scalp using EEG recordings from a nonclinical population. We propose that, regardless of frequency, spindles recorded either intracranially or at the scalp are more likely to start on the down to up transition and we describe a theta burst (TB) distinct from spindles that can accompany the up to down transition, especially in N2 sleep.

\section{Materials and Methods}

Intracranial recordings. Stereoencephalography (SEEG) was obtained in 10 patients ( 8 female; mean \pm SD age: $38.7 \pm 12.7$; Table 1 ) undergoing evaluation for pharmacoresistant epilepsy at Massachusetts General Hospital; La Timone Hospital, Marseille, France; or Neurological Hospital, Lyon, France. At Massachusetts General Hospital, electrode contacts were localized using CT of the implanted electrodes superimposed on preoperative MRI (Dykstra et al., 2012). Each SEEG electrode had either 8 (5 $\mathrm{mm}$ center-to-center spacing) or 6 ( $8 \mathrm{~mm}$ spacing) contacts. Each contact was $1.28 \mathrm{~mm}$ in diameter and $2.4 \mathrm{~mm}$ long. Signals were sampled at $500 \mathrm{~Hz}$ and band-pass filtered from 0.33 to $128 \mathrm{~Hz}$. At La Timone Hospital, localization of electrode contacts was performed using MRI and CT of implanted electrodes. For one patient, localization was determined using preoperative MRI and surgical planning. Each electrode had either 10 or 15 contacts (3.5 mm center-to-center spacing). Each contact was $0.8 \mathrm{~mm}$ in diameter and $2 \mathrm{~mm}$ long. The recordings were sampled at 256, 512, or $1024 \mathrm{~Hz}$. At the Neurological Hospital, electrode localization was determined directly from stereotactic teleradiographs without parallax performed within the stereotactic frame (Talairach and Tournoux, 1998). These locations were superimposed onto the preimplantation 3T structural MRI (3D MPRAGE T1 sequence) after alignment with the skull. The locations of cortical and thalamic contacts were determined by reference to the atlases of Duvernoy (1999) and Morel et al. (1997). Each electrode had either 10 or 15 contacts $(3.5 \mathrm{~mm}$ center-to-center spacing). Each contact was $0.8 \mathrm{~mm}$ in diameter and 2 $\mathrm{mm}$ long. The recordings were sampled at $256 \mathrm{~Hz}$ and bandpass filtered from 0.33 to $128 \mathrm{~Hz}$. Informed consent was obtained from all patients.

SEEG recordings were bipolar between adjacent contacts spanning the cortical ribbon. These "transcortical bipolar contacts" provide relatively focal measurements of the local field potentials generated in the transected cortex (Mak-McCully et al., 2015). The polarity of bipolar derivations was inverted if necessary to ensure that DS [as confirmed with decreased high gamma (HG); see below] were negative. This produced recordings with a relatively consistent relationship to the underlying cortical generators, as evidenced by the consistent phase relation between HG and TB (see below) and chosen as described previously (MakMcCully et al., 2015). Only channels with both slow oscillations and spindles apparent to visual inspection were included for analysis. Channels were excluded if a clinical electroencephalographer judged significant interictal activity, pathological background changes, or early involvement in the ictal discharge. At each site, sleep scoring was performed by clinical experts (S.S.C., H.B., or M.R.) using examination of 

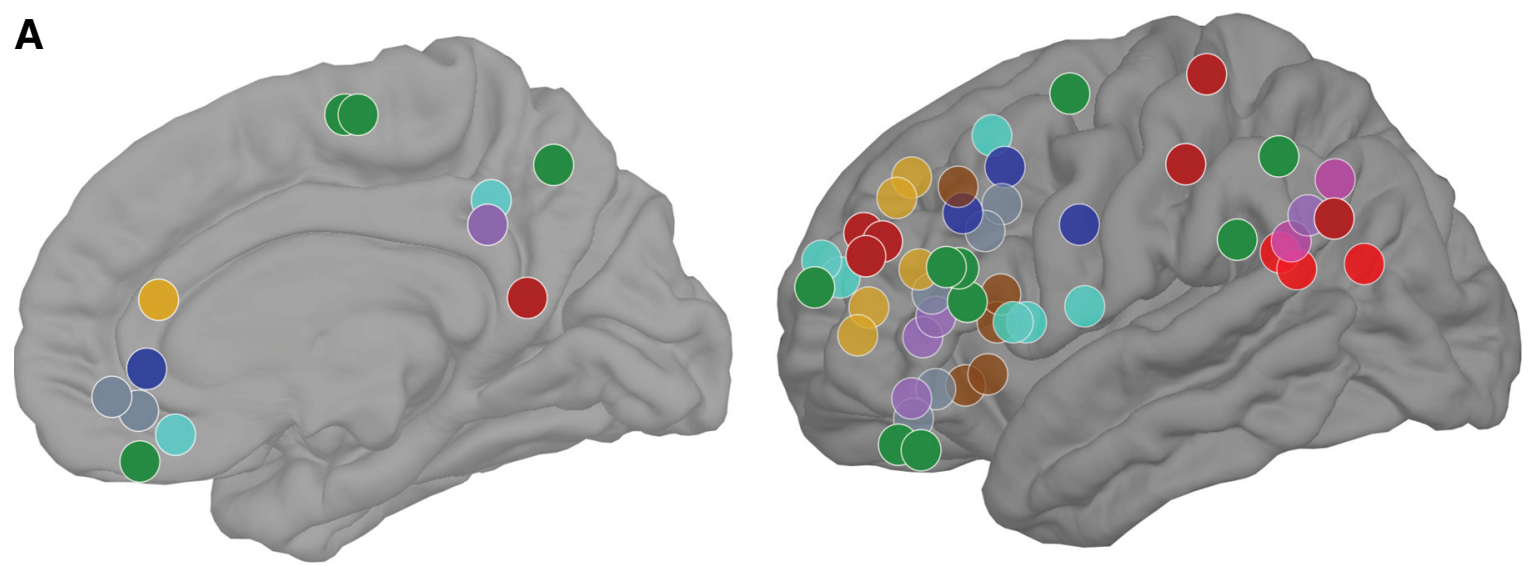

B

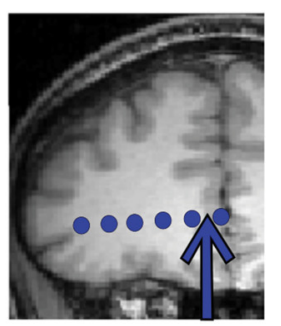

C

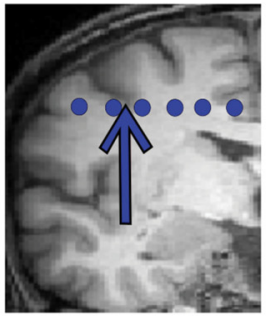

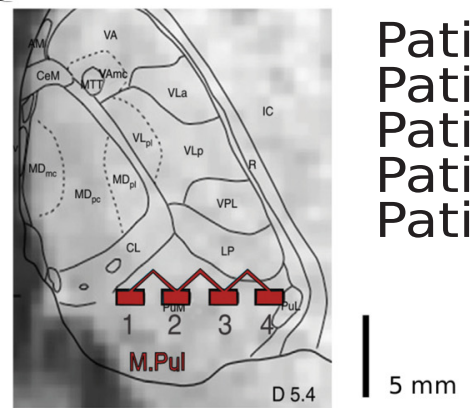

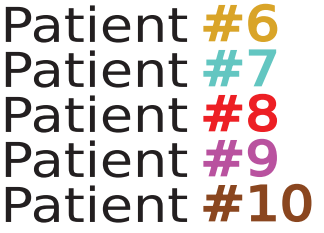

Figure 1. Bipolar SEEG recordings obtained from epileptic patients. $A$, Locations of 60 cortical bipolar recordings from 10 patients with intracranial electrodes. $\boldsymbol{B}$, Illustration of bipolar transcortical derivation used throughout the study, with arrows indicating two cortical bipolar channels from Patient 3. C, Illustration of bipolar recordings from Patient 1 from the pulvinar of the thalamus.

bipolar electrodes $(n=7)$ or scalp EEG with EOG/EMG when available $(n=3)$. Analyses were performed on the N2 and N3 sleep periods only (Silber et al., 2007).

In total, 60 cortical bipolar SEEG channels obtained from 10 patients and eight thalamic (mainly pulvinar) bipolar channels from three of the 10 patients during NREM sleep were included for analysis. The locations of all cortical bipolar channels are shown in Figure $1 A$, as well as examples of bipolar derivations for cortical (Fig. 1B) and thalamic (Fig. 1C) sites. On average, each patient had six cortical channels (ranging from two to 13) and $120.6 \mathrm{~min}$ of NREM sleep from one night (ranging from 26.5 to $240 \mathrm{~min}$ ). DSs and spindles were detected on each channel separately using previously described methods (and see below) (Mak-McCully et al., 2017).

Scalp EEG recordings. Scalp EEG data were recorded during sleep from three healthy subjects (one female). Written informed consent approved by the Partners Healthcare Network was obtained for all subjects before their participation. Subjects wore a 70-channel EEG cap with a modified 10-20 montage (Elekta Neuromag). Data were referenced to left mastoid. Magnetoencephalographic data were collected simultaneously but are not reported here. Periods of N2 sleep were identified according to standard criteria (Iber et al., 2007). Gross artifacts were removed by visual inspection.

DS detection. DSs were detected on each channel as follows: (1) apply a zero-phase eighth-order Butterworth filter from 0.1 to $4 \mathrm{~Hz}$; (2) select consecutive zero crossings within 0.25- $3 \mathrm{~s}$; and (3) calculate amplitude peak between zero crossings and retain only the bottom $20 \%$ of peaks for intracranial recordings or the bottom $10 \%$ of peaks for scalp EEG recordings.

For DS detection in intracranial recordings, only periods of N2 and N3 sleep free of visually identified epileptiform discharges were used. Bipolar SEEG channels exhibiting DSs were also required to show decreases in power within $\mathrm{HG}$, defined as $60-100 \mathrm{~Hz}$, exceeding $1 \mathrm{~dB}$ within $\pm 250 \mathrm{~ms}$ of the negative DS peak. Sixty such channels were identified, showing mean decreases in $\mathrm{HG}$ power during DS troughs of $-3.18 \mathrm{~dB}$ (range, -1 to -8$)$.
Spindle detection. The current clinical standard for sleep scoring adopted by the American Academy of Sleep Medicine is 11-16 Hz (Silber et al., 2007), but the major previous studies describing sleep spindles using intracranial recordings in humans adopted $9-16 \mathrm{~Hz}$ (Andrillon et al., 2011; Piantoni et al., 2017) or 10-16 Hz (Mak-McCully et al., 2017; Hagler et al., 2018). Recent analyses with scalp recordings of fast versus slow spindles have also used either 9-15 Hz (Mölle et al., 2011; Klinzing et al., 2016) or 10-16 Hz (Cox et al., 2014a) or even 9-16 Hz(Yordanova et al., 2017), but in the majority of cases, with the division between fast and slow spindles at $12 \mathrm{~Hz}$. Here, we consider spindles as $10-16 \mathrm{~Hz}$ events and define spindles $\leq 12 \mathrm{~Hz}$ as slow. Recordings were notch filtered (either $49-51 \mathrm{~Hz}$ or $59-61 \mathrm{~Hz}$, depending on country of origin) and then band-pass filtered at $10-16 \mathrm{~Hz}$ using a zero-phase frequency domain filter (transition bands 30\% of cutoff frequency). Taking the absolute value of this filtered signal produced a spindle-band amplitude envelope. This envelope was convolved with a $400 \mathrm{~ms}$ Tukey window and the median amplitude was subtracted and normalized by the median absolute deviation. This signal was used to detect the onset and offset of putative spindle epochs. To detect the middle of spindle epochs, we convolved the amplitude signal with a $600 \mathrm{~ms}$ Tukey window, normalized as before, and identified peaks with magnitude larger than 2 for intracranial recordings and larger than 1 for scalp EEG recordings. Then, we defined the onset and offset as $40 \%$ of the peak amplitude of the original spindle amplitude envelope. Any overlapping or duplicate epochs were resolved and epochs $<300 \mathrm{~ms}$ were excluded. We then applied a series of strict exclusion criteria for putative spindle epochs. These included removing any epochs that also exceeded 5 for a low $(4-8 \mathrm{~Hz})$ or high $(18-25 \mathrm{~Hz})$-amplitude envelope. We also required 5 peaks in a broad-band filtered signal $(4-25 \mathrm{~Hz})$ with an amplitude greater than the median absolute deviation per channel and at least $25 \%$ amplitude of the largest peak. Spindles in the thalamus were detected using a modified version of this detector as described previously (Mak-McCully et al., 2017).

TB detection. TBs were detected by modifying a previously reported spindle detector (Andrillon et al., 2011). Our procedure was as follows: 
(1) apply a zero-phase eighth-order Butterworth filter from 5 to $8 \mathrm{~Hz}$ (range selected to minimize overlap with delta and spindle content); (2) calculate the mean of the Hilbert envelope of this signal smoothed with a Gaussian kernel (300 ms window; $40 \mathrm{~ms} \sigma$ ); (3) detect events with a \pm 3 SD threshold for the peak and identify the start and stop times with a \pm 1 SD threshold; (4) only include events with a duration between $400 \mathrm{~ms}$ and $1 \mathrm{~s}$; and (5) for each band-pass-filtered peak in putative burst, calculate the preceding trough-to-peak deflection and only take events that have at least 3 peaks exceeding $25 \%$ of the maximum deflection. We also required bipolar SEEG recordings to have at least 50 TBs before calculating average theta frequency or the proportion of theta events associated with DSs, which excluded four of 60 cortical channels.

Phase-amplitude coupling (PAC). For the intracranial recordings, we correlated the phase of either spindle $(10-16 \mathrm{~Hz})$ or theta $(5-8 \mathrm{~Hz})$ with the analytic amplitude in $60-100 \mathrm{~Hz}$ for all cortical channels across patients. We chose $60-100 \mathrm{~Hz}$ to keep the range consistent across patients and because our lowest sampling frequency was $256 \mathrm{~Hz}$. Only channels that had at least 30 theta events and 30 spindles were included (58 of 60 cortical channels). We band-pass filtered our data in the theta-, spindle-, and gamma-frequency ranges using finite impulse response filters with an order equal to the duration of three cycles of the lowest frequency. We used the Hilbert transform to extract the analytic signal from our bandpassed data, took the phase angle from our theta and spindle band-passed data, and the amplitude from our HG band-pass signal. Correlations between the phase of the lower frequency signal and HG amplitude were evaluated across a duration equal to the first two cycles of the lower frequency range per signal across all detected events for each channel. The observed PAC measure was calculated by taking the length of the average complex vector of the low-frequency phase, weighted by the corresponding high-frequency power time series (Canolty et al., 2006). Significance was assessed for each channel and event type using nonparametric permutation statistics. Specifically, for each channel and event type, the phase time series was randomly offset relative to the power time series and PAC was recalculated 1000 times, generating a null distribution against which to compare our observed PAC measure. The preferred phase was determined only for channels with a PAC-Z value $>3(p<$ $0.002)$.

Time domain and spectral analyses. We created event-related histograms to quantify the timing of intracranially recorded spindle or theta events relative to all intracranially recorded DS troughs. For each bipolar SEEG recording, we required at least 30 events associated with a DS within $\pm 1 \mathrm{~s}$ of the DS trough to be included in the grand average histograms. Furthermore, we required at least 20 events within $\pm 500 \mathrm{~ms}$ to assess whether spindle (theta) events were more likely to start $500 \mathrm{~ms}$ after (before) the DS trough using a two-way binomial test. Binomial tests were corrected for multiple comparisons using Bonferroni correction $(\alpha=0.05)$ for each grapho-element type. Data processing and analysis were performed in MATLAB and time-frequency plots were created using EEGLAB (Delorme and Makeig, 2004).

We also examined the spectral profile of periods before DSs. Powerspectral densities (PSDs) were computed for the epoch 500 to $0 \mathrm{~ms}$ before the DS trough. For each channel, these were ranked and quartiled by the power in the $4-12 \mathrm{~Hz}$ band. PSDs in the first and fourth quartile were normalized as $z$-scores and averaged over DSs. The difference between the quartiles is plotted in Figures $2 G$ (SEEG) and $5 E$ (scalp EEG).

Experimental design and statistical analysis. Linear mixed-effects models with patient specified as random effect were implemented in $\mathrm{R}$ to estimate descriptive statistics such as overall frequency, duration, and rate of occurrence, as well as for testing differences between frontal and parietooccipital electrodes.

\section{Results}

\section{Identifying short TBs before DSs in the cortex}

Visual inspection of average spectrograms \pm 2 s relative to all DS troughs in intracranial recordings showed increases within the $5-10 \mathrm{~Hz}$ range $\sim 250 \mathrm{~ms}$ before the negative peak (Fig. $2 A, D$, cyan arrows). However, inferring oscillatory activity from such representations can be misleading (Jones, 2016) because the sharp decline in the pretrough part of the DS could contain nonoscillatory power in the theta band (Cox et al., 2014b). To confirm that this increase was associated with an oscillatory component and was not just an artifact of the ensuing DS LFP waveform, we looked for the presence of oscillations in the average of the original LFP time locked to a filtered theta peak $(5-8 \mathrm{~Hz})$. We implemented this by sorting DSs according to previous theta power and averaging across events within a quartile time locked to the first band-passed theta peak preceding the DS trough. This unfiltered average revealed clear oscillatory activity within the theta range, showing two to three peaks across the majority of channels for the top quartile and often absent in the lowest (Fig. $2 B, E$ ). Theta oscillations were also apparent at the level of single DSs selected from the top quartile (Fig. $2 B, E$, insets, cyan arrows).

To further characterize this observed intracranially recorded theta oscillation during NREM sleep, we applied a theta detector to each channel (see Materials and Methods). Descriptive statistics for detected theta events are shown per patient in Table 2 and the overall estimates for frequency, duration, and rate of occurrence are as follows (mean $\pm \mathrm{SD}$ ): $6.33 \pm 0.45 \mathrm{~Hz}, 672 \pm 28 \mathrm{~ms}$, $1.25 \pm 0.39 / \mathrm{min}$. Interestingly, frontal channels exhibited lower overall frequency compared with parietooccipital channels, with estimated frequencies of 6.26 and 6.5 , respectively $(t=-5.6, p=$ $2.14 \mathrm{e}-08$, mixed-effects model with patient as random effect). As expected, frontal channels also showed lower overall spindle frequency compared with parietooccipital $(t=-3.14, p=0.002)$, with estimated overall frequencies of 12.26 and $12.65 \mathrm{~Hz}$. To further verify that the pre-DS oscillations were the result of theta and not slower spindles, for each channel, we sorted DSs by power in $4-12 \mathrm{~Hz} 500 \mathrm{~ms}$ before the DS trough. This range includes both theta and slow spindle frequencies and thus would detect either. We then calculated the average PSD across all DSs, per quartile. The difference of the top and bottom quartiles reveals a center of frequency at $6 \mathrm{~Hz}$ across channels $(2 \mathrm{G})$, indicating that the pre-DS oscillations are theta rather than slow spindles.

In Figure 2, $C$ and $F$, we superimpose all detected theta traces, unfiltered and locked to the deepest trough in the theta event for two example bipolar SEEG channels. Some channels exhibited a downward trend in the average (Fig. $2 F$ ), suggesting that DS tends to follow the deepest trough, whereas others do not (Fig. $2 C$ ). This difference illustrates that, whereas some detected theta events were associated with DSs, others were not, and this varied within and between channels. We also observed from post hoc analyses that some channels exhibited larger amplitude and more prolonged theta oscillations in the raw LFP for N2 versus N3 DSs (Fig. 3A). This was corroborated with a greater number of peaks in detected TBs on average per channel for N2 compared with N3 $(t=-4.33, p=1.49 \mathrm{e}-05$, mixed-effects model with patient as random effect and channel as nested random effect). Additionally, we found that there was significantly greater theta power prior ( $-500 \mathrm{~ms}$ to 0$)$ to the DS trough for N2 compared with N3 DSs (Fig. $3 B ; t=-3.13, p=0.002$, mixed-effects model). However, the rate of detected theta event occurrence was not different between N2 and N3 $(t=-1.2, p=0.23)$. That is, although the number of events did not differ between N2 and N3, TBs were longer and larger in N2.

\section{Theta and spindles show different temporal relationships with DSs}

Because slow oscillations during sleep are known to group higher-frequency rhythms, we investigated how often our de- 
A

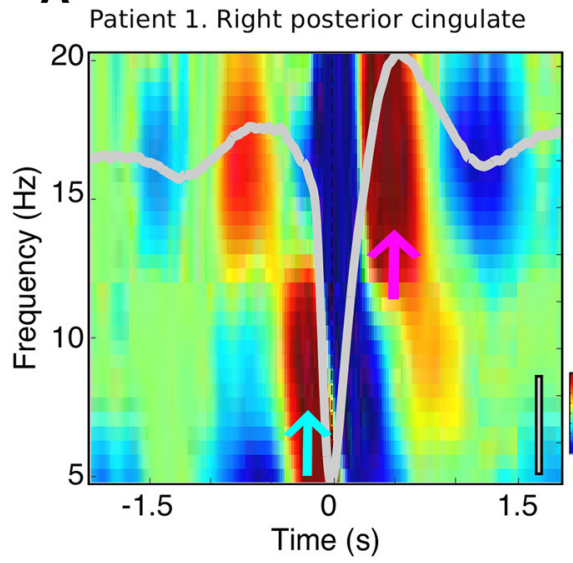

D

Patient 2. Left inferior frontal gyrus
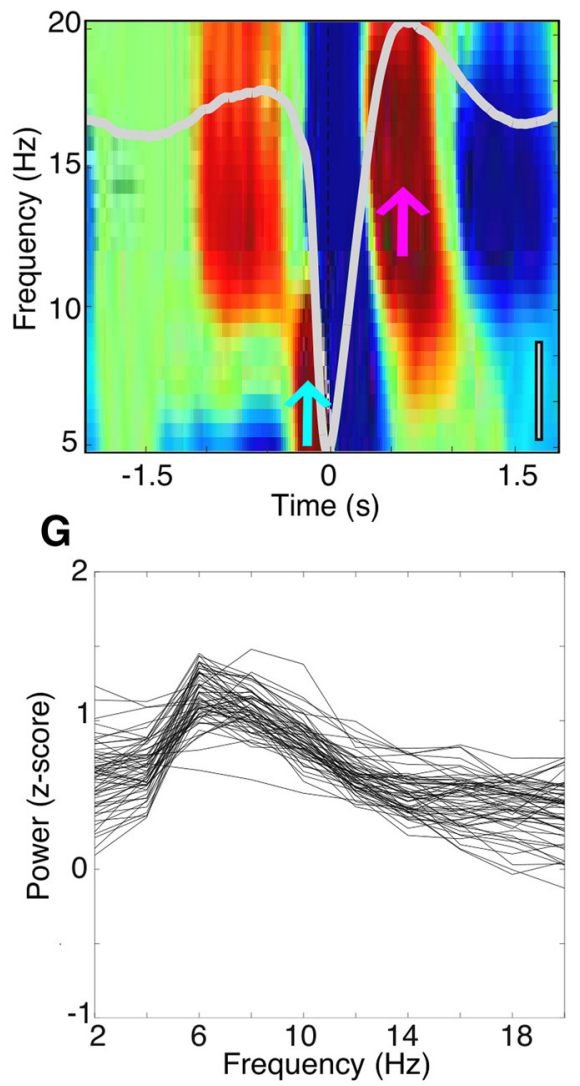

B

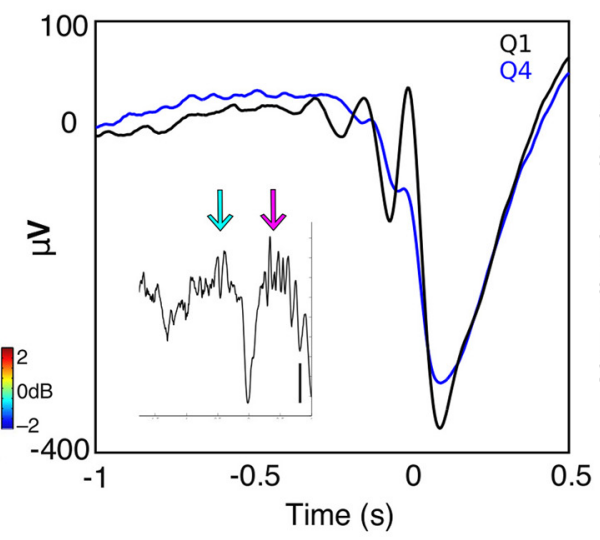

E

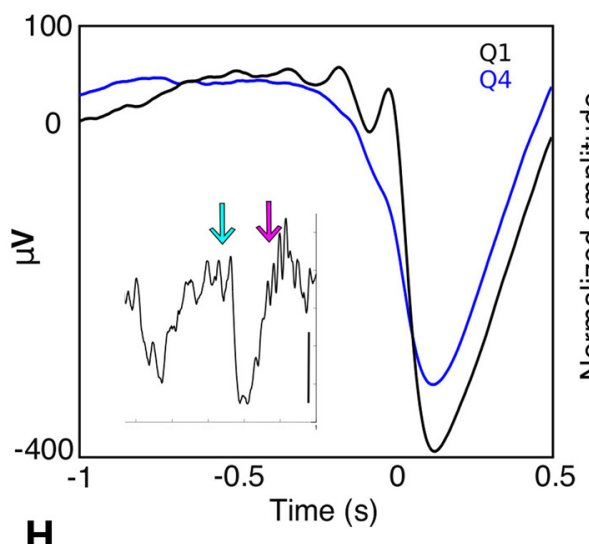

H

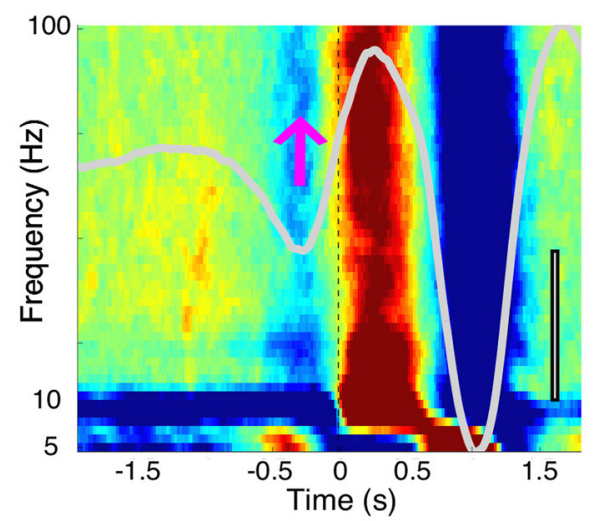

C

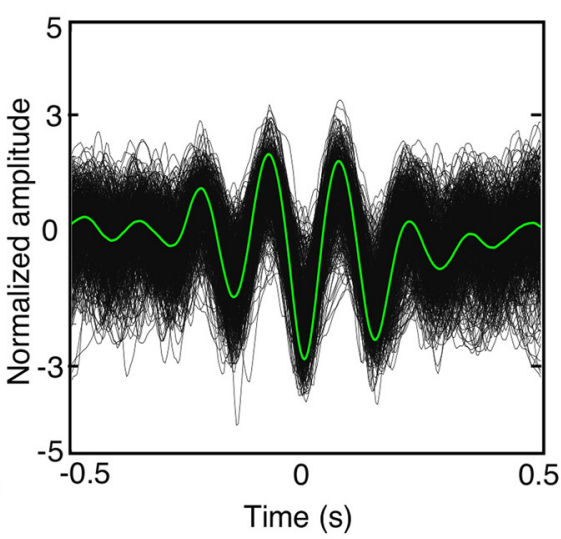

F

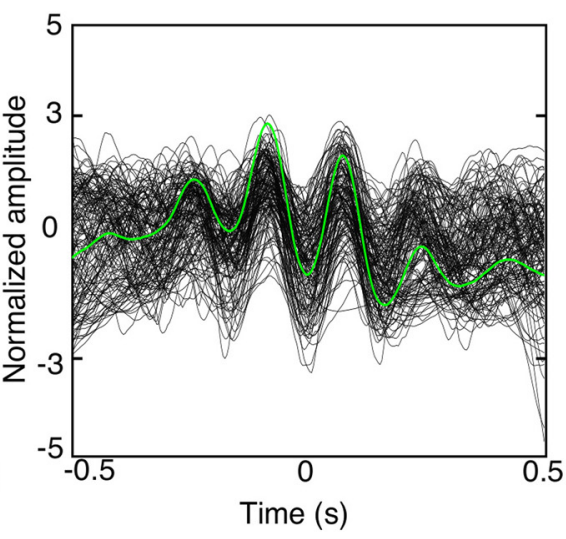

Figure 2. Cortical theta during NREM sleep. $\boldsymbol{A}-\boldsymbol{C}$, Patient 1, right posterior cingulate. $\boldsymbol{D}-\boldsymbol{F}$, Patient 2, left inferior frontal gyrus. For both $\boldsymbol{A}(n=2084)$ and $\boldsymbol{D}(n=1265)$, time-frequency plots locked to DS troughs reveal increases in the theta range (cyan arrows) immediately before the trough and centered within spindle range (pink arrows) from 0.5 to $1 \mathrm{~s}$ after the trough (and more weakly from $-1 \mathrm{to}-0.5 \mathrm{~s}$ before the trough due to a preceding DS $($ see $\boldsymbol{H})$ ). The entire epoch was used as baseline. The average of all DSs is overlaid in light gray, gray scale bars indicate $100 \mu \mathrm{V}$. $\boldsymbol{B}, \boldsymbol{E}$, Average, unfiltered LFP time-locked to the first filtered positive theta peak before the DS trough. Black indicates the top quartile $(n=521$ for $\boldsymbol{B}, n=316$ for $\boldsymbol{E})$, blue the bottom quartile of DSS with prior theta power. Insets reveal a single trace from the top quartile. Scale bars, $200 \mu \mathrm{V}$ for inset, time ranges from -2 to $+0.5 \mathrm{~s}$ of the DS trough. Cyan and pink arrows indicate theta events and spindles, respectively. Positive potentials indicate cortical surface positivity. $\boldsymbol{C}, \boldsymbol{F}$, Raw LFP of detected theta events locked to the deepest trough, $z$-normalized. Average shown in green for $\boldsymbol{C}(n=$ 509) and $\boldsymbol{F}(n=148)$. G, Pre-DS spectra. Plotted are the differences of the first and fourth quartile average power spectral densities of $500 \mathrm{~ms}$ pre-DS, when ranked by the amount of $4-12 \mathrm{~Hz}$ power they contain. Each trace represents the difference of average PSDs for one channel in one patient; all 60 cortical channels are shown. In nearly all channels, power peaks at $6 \mathrm{~Hz}$. $\boldsymbol{H}$, Average time-frequency plot across patients time locked to spindle starts from -1.25 to -0.75 s before DS troughs. DSs can be seen at -0.25 s before these spindle starts, marked by the pink arrow. Note that these spindle-preceding DSs also precede the TBs and the DSs shown in $A$ and $D$ by $\sim 1$ s, as shown by the two negative deflections in the superimposed gray waveform (color scale indicates \pm $1 \mathrm{~dB})$. Scale bar, $100 \mu \mathrm{V}$.

tected TBs occurred in relation to DSs recorded intracranially. To quantify this, we created event-related histograms for each bipolar channel by relating the start of TBs to DS troughs. For example, a recording from Patient 1 in the right middle frontal gyrus shows that, when TBs are detected around DSs, they are more likely to start $\sim 300 \mathrm{~ms}$ before the DS trough (Fig. $4 A$ ). At the same cortical location, the likelihood of slow spindles (Fig. 4B), fast spindles (Fig. 4C), or all spindles (Fig. 4D) starting between 
Table 2. Theta burst characteristics

\begin{tabular}{|c|c|c|c|c|c|c|}
\hline Patient & $\begin{array}{l}\text { No. of cortical } \\
\text { channels }\end{array}$ & $\begin{array}{l}\text { No. of thalamic } \\
\text { channels }\end{array}$ & $\begin{array}{l}\text { NREM } \\
\text { time (min) }\end{array}$ & $\begin{array}{l}\text { Cortical theta } \\
\text { rate (1/min) }\end{array}$ & $\begin{array}{l}\text { Cortical theta } \\
\text { frequency }(\mathrm{Hz})\end{array}$ & $\begin{array}{l}\text { Cortical theta } \\
\text { duration (ms) }\end{array}$ \\
\hline 1 & 7 & 3 & 240 & $1.83(0.43)$ & $6.44(0.2)$ & 669 (22) \\
\hline 2 & 13 & 3 & 146 & $0.78(0.3)$ & $6.13(0.1)$ & $679(29)$ \\
\hline 3 & 4 & 0 & 40 & $1.24(0.36)$ & $6.05(0.1)$ & $688(21)$ \\
\hline 4 & 5 & 0 & 26 & $1.09(0.14)$ & $6.39(0.14)$ & $646(40)$ \\
\hline 5 & 7 & 0 & 58 & $1.07(0.27)$ & $6.37(0.12)$ & 622 (19) \\
\hline 6 & 7 & 0 & 144 & $0.61(0.34)$ & $6.32(0.14)$ & $701(29)$ \\
\hline 7 & 8 & 0 & 161 & $1.28(0.35)$ & $6.21(0.19)$ & $696(22)$ \\
\hline 8 & 3 & 0 & 90 & $1.44(0.2)$ & $6.62(0.14)$ & $640(25)$ \\
\hline 9 & 2 & 2 & 202 & $1.64(0.79)$ & $6.65(0.13)$ & $672(1)$ \\
\hline 10 & 5 & 0 & 98 & $0.95(0.22)$ & $6.25(0.1)$ & 667 (27) \\
\hline Avg: & $6.1(3.1)$ & - & $120.5(70.27)$ & $1.2(0.38)$ & $6.34(0.2)$ & $668(25.3)$ \\
\hline
\end{tabular}

Parentheses indicate SD.

A Patient 9. Right supramarginal gyrus

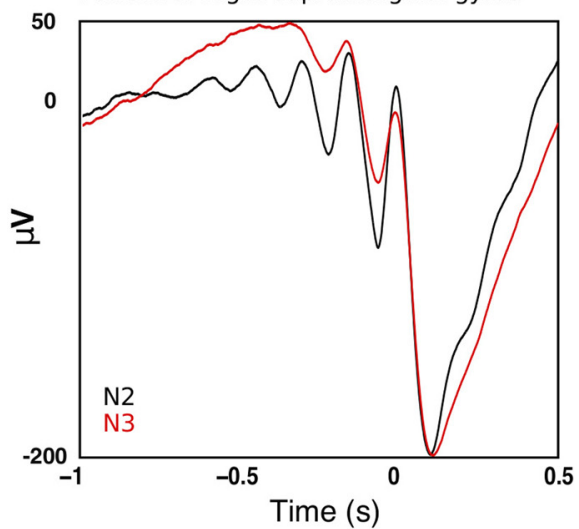

Patient 8. Right angular gyrus

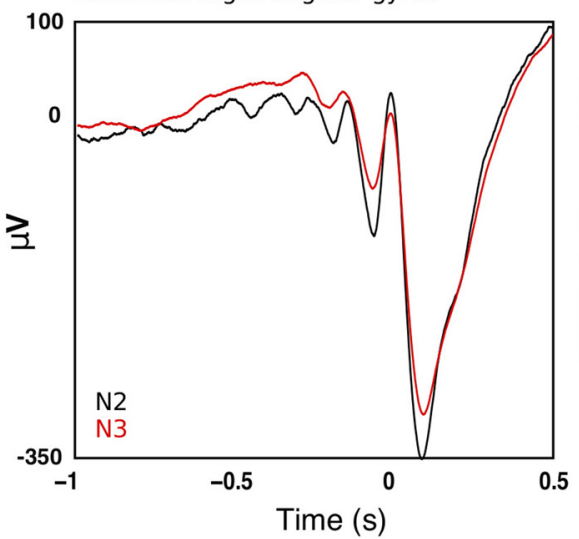

B

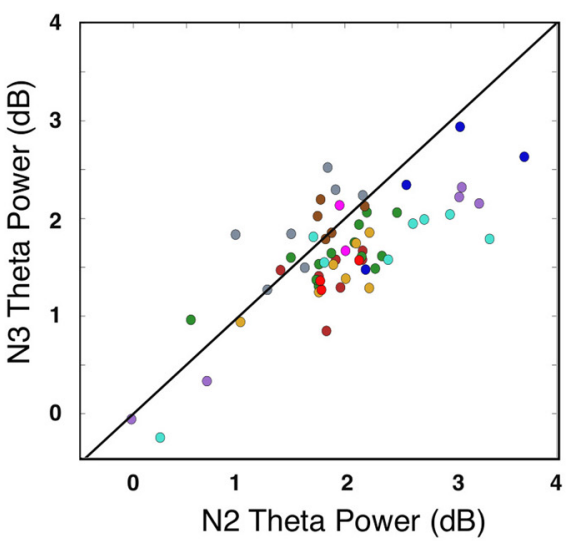

Figure 3. Comparing N2 and N3 TBs. A, Theta oscillations before DS troughs were more pronounced for N2 than for N3 DSs. Average waveforms of the DS with the top quartile of prior theta power are shown from two patients within N2 in black ( $n=677$ in Patient 9 and 174 in Patient 8 ) and N3 in red ( $n=913$ in Patient 9 and 635 in Patient 8 ). Unfiltered averages are locked to the filtered theta peak just preceding the DS trough. $\boldsymbol{B}$, Power within theta $(5-8 \mathrm{~Hz})$ range $-500 \mathrm{~ms}$ to 0 relative to DS trough for each channel (channels from a given patient have the same color). Most dots are below the diagonal, indicating that theta power was greater for N2 than for N3 ( $t=-3.13, p=0.002$, mixed-effects model with patient as random effect and channel as nested random effect).

$-500 \mathrm{~ms}$ and 0 is greatly reduced compared with after the DS trough.

Of 60 cortical recordings, 35 channels from seven patients had at least 20 TBs within \pm 500 ms of the DS trough, none of which was significantly more likely to start after the DS trough. However, 14 of the 35 channels from five patients were more likely to have TBs start before the DS trough (binomial test, Bonferroni adjusted $p<0.05$ ). The proportion of TBs occurring before the DS trough for these channels was not significantly different between the frontal and parietooccipital regions $(t=1.1, p=0.27)$.

Previous work (Mölle et al., 2011; Klinzing et al., 2016) asserts that spindles have different temporal relationships with DSs depending on spindle frequency; with slower spindles $(\leq 12 \mathrm{~Hz})$ occurring on the up to down transition and faster spindles $(>12$ $\mathrm{Hz}$ ) occurring on the down to up transition. To test this hypothesis, we selected from the 60 cortical recordings, the 35 channels from seven patients who had at least 20 slow spindles within \pm $500 \mathrm{~ms}$ of the DS trough. None of these channels showed slower spindles that were significantly more likely to start before the DS trough. However, slower spindles recorded by 20 of the 35 channels from 6 patients were more likely to start after the DS trough (Bonferroni-adjusted $p<0.05$ ). If all spindles were grouped together, then those recorded by $39 / 49$ channels from 10 patients were significantly more likely to start after the DS trough (Bonferroni-adjusted $p<0.05)$. Neither slower spindles $(t=$
$-0.44, p=0.66)$ nor all spindles $(t=-1.25, p=0.21)$ showed significant differences between frontal and parietooccipital regions in the proportion of spindle events occurring after DS troughs.

Normalizing each event-related histogram per channel by the total number of counts in the $\pm 1 \mathrm{~s}$ time window and pooling histograms across all cortical bipolar channels from 10 patients revealed similar results (Fig. $4 E-H$ ): TBs initiate before DS troughs and spindles, both slow and fast, initiate after. Significance was assessed by Bonferroni correction $(p<0.05)$ across time bins within each event type. Time bins with significant likelihood of TBs starting were centered around -450 and $-350 \mathrm{~ms}$ before the DS trough (Fig. $4 E$ ). In contrast, slower spindles were significantly more likely to start 350-450 ms after the DS trough (Fig. $4 F$ ) and faster spindles were significantly likely to start between bins centered 150-550 ms after the DS trough (Fig. 4G). This confirms that spindles are more likely to start during the transition from down to USs, whereas TBs start just before the transition to a DS.

Some time bins (Fig. $4 B-D, G, H$ ) showed an increased likelihood of spindles starting from $\sim-1.25 \mathrm{~s}$ to $-0.75 \mathrm{~s}$ before DS troughs. To determine whether this increase was due to a previous DS, we identified the "early" spindles in question as those that began at $\sim-1 \mathrm{~s}$ before down state troughs (between $-1.25 \mathrm{~s}$ and $-0.75 \mathrm{~s}$ relative to the DS trough). Then, we generated a timefrequency plot for the activity surrounding these spindles for each 
A B

Patient 1. Right middle frontal gyrus

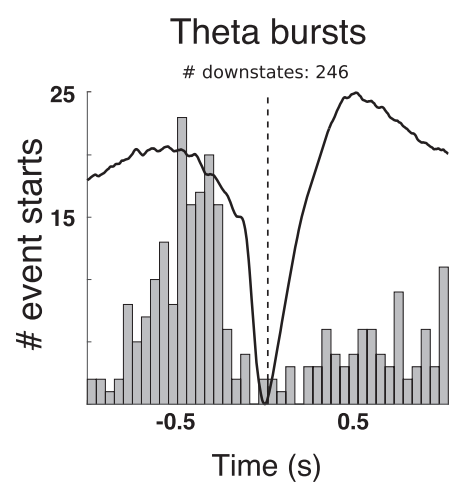

E

Theta bursts

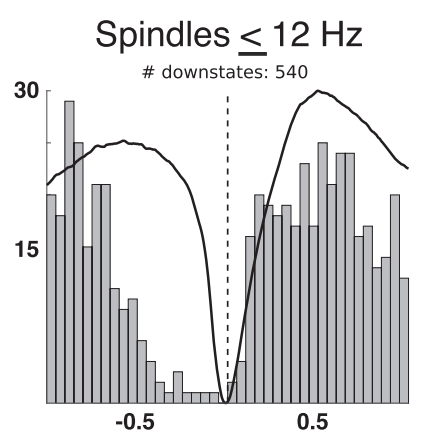

$\mathbf{F}$

\section{Spindles $\leq 12 \mathrm{~Hz}$}

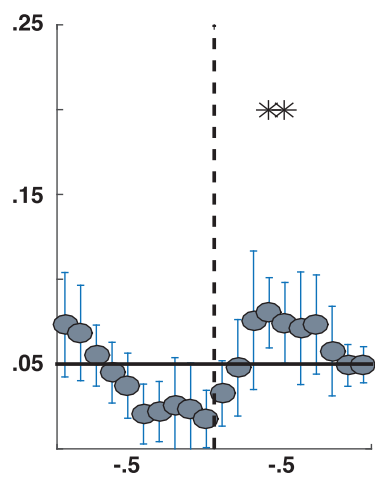

C
D

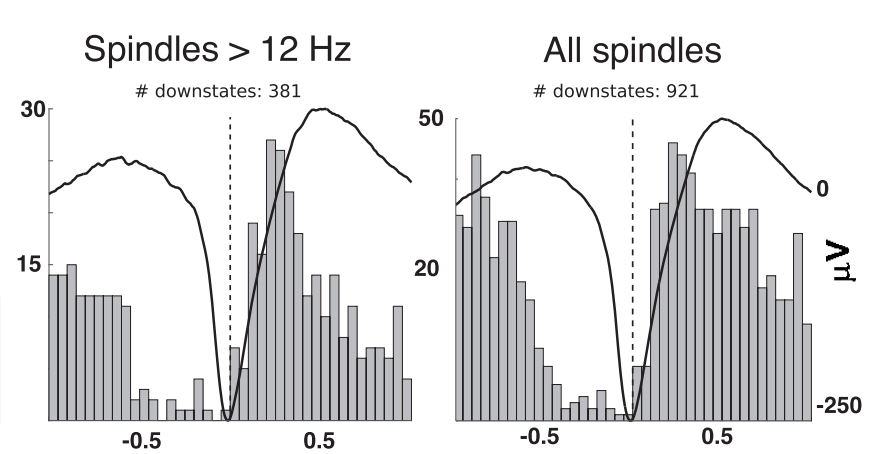

G

Spindles $>12 \mathrm{~Hz}$
H
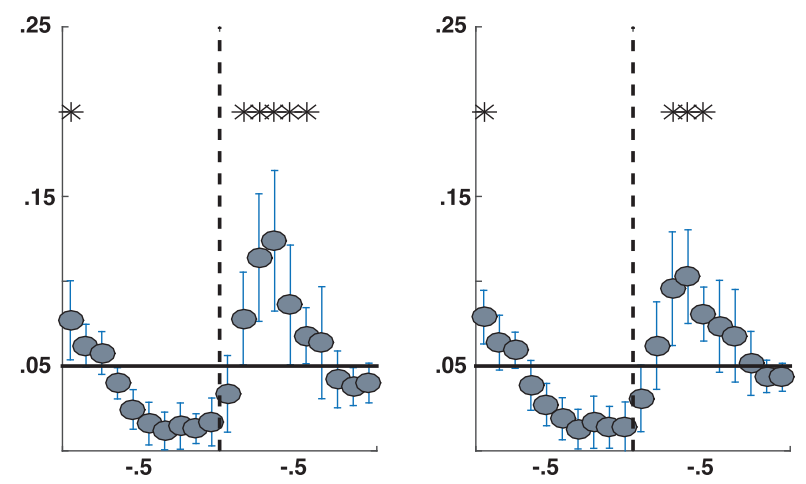

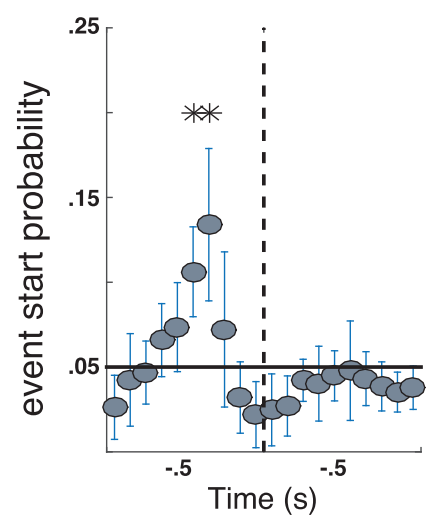

I

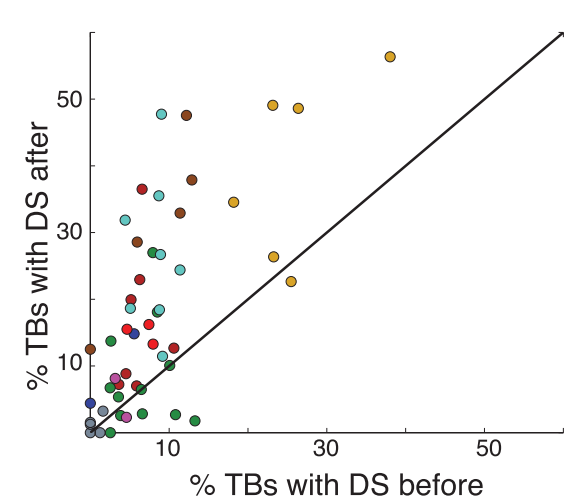

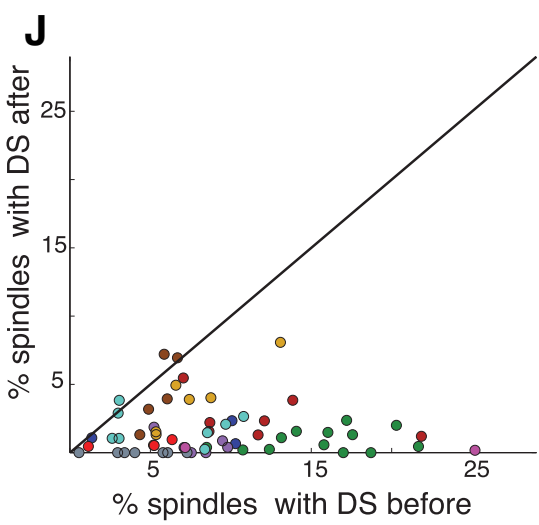

Figure 4. Cortical theta precedes DSs and both slow and fast spindles follow. $\boldsymbol{A}-\boldsymbol{D}$, Event-related histograms showing the timing of the start of $\operatorname{TBs}(\boldsymbol{A})$, spindles $\leq 12 \mathrm{~Hz}(\boldsymbol{B})$, spindles $>12 \mathrm{~Hz}$ $(\boldsymbol{C}$, and all spindles (D) relative to the DS trough at a single bipolar channel in the right middle frontal gyrus of Patient 1 during both N2 and N3 sleep. $\boldsymbol{E}-\boldsymbol{H}$, Histograms from all channels normalized by the total number of counts $\pm 1 \mathrm{~s}$ and pooled in $100 \mathrm{~ms}$ bins. The black line indicates chance level and probability estimates per bin across channels were calculated using linear mixed-effects models. Stars indicate bins where events occur significantly more than chance (Bonferroni adjusted, $p<0.05$ ). Error bars indicate $95 \%$ confidence intervals (Cls). I, Scatterplot for each channel of the proportion of TBs with the DSs within $500 \mathrm{~ms}$ after ( $y$-axis) versus the proportion with the DS within $500 \mathrm{~ms}$ before ( $x$-axis). J, Same as I but for spindles. All cortical channels with at least 50 events were included. Most channels (dots) in I are above the diagonal, indicating that the DS trough usually occurs after TB onset; in contrast, most channels in Jare below the diagonal, indicating that the DS trough usually occurs before spindle onsets.

channel and averaged them across the 33 channels in six patients who had at least 50 such spindles (Fig. $2 H$ ). A DS is clearly present in the average time-frequency plot, peaking $\sim .25 \mathrm{~s}$ before the onset of these early spindles. The same plot shows another DS at $\sim 1 \mathrm{~s}$ following early spindle onset; this is the DS that was used to identify the early spindles in the first place, corresponding to the $\mathrm{DS}$ at $0.0 \mathrm{~s}$ in plots $2 \mathrm{AD}$. The early spindle power increase pre- cedes the theta band increase in this plot, as well as those triggered on the main DS (Fig. 2A,D). In summary, we demonstrate that there is a sequence of sleep grapho-elements, typically theta-DSspindle, but sometimes DS1-spindle1-theta-DS2-spindle2. The second, longer sequence is expected given that, especially in stage N3, DSs are well known to occur rhythmically at $\sim 1 \mathrm{~Hz}$, comprising the slow oscillation. 
Next we investigated how often TBs or spindles occur around DSs. Only channels that had at least 50 occurrences of each event type (theta or spindle) were included ( $n=9$ patients, 49 cortical channels). DS masks were marked by DS troughs and spindle and theta event masks marked by estimated start times. We found that, on average across patients, $24 \%$ of detected TBs began within \pm 500 ms of a DS trough, with $7.7 \%$ of TBs occurring after a DS and $17.8 \%$ occurring before (Fig. $4 I$ ). In contrast, $10 \%$ of detected spindles began within $\pm 500 \mathrm{~ms}$ of a DS trough, with $8.7 \%$ of spindles occurring after a DS and $1.7 \%$ occurring before (Fig. $4 J$ ). There was a significantly greater proportion of TBs that fell within \pm 500 ms of a DS trough than spindles (paired $t$ test, $p=2.4 \mathrm{e}-05$ ). There was substantial interpatient variability for both events, especially for TBs. Despite this variability, most patients exhibited similar temporal relationships with DSs.

\section{Relation of TBs and spindles recorded in scalp EEG to DSs}

To ensure that that our findings generalize to nonpatient populations and to contextualize our results within the framework of more commonly recorded noninvasive measures, we detected events recorded using scalp EEG in three healthy human participants and recalculated eventrelated histograms, as shown in Figure 4, E-H. Replicating the SEEG results reported above, normalized peri-DS histograms revealed divergent patterns for TBs and spindles recorded at the scalp (Fig. 5): TBs initiate before DS troughs, whereas spindles begin afterward. Significance was assessed by Bonferroni correction $(p<0.05)$ across time bins within each event type. TBs had a significant likelihood of starting 500-300 ms before the DS trough (Fig. 5A). In contrast, slower and faster spindles were significantly more likely to start during time bins centered on 450 and $350 \mathrm{~ms}$, respectively, after the DS trough (Fig. $5 \mathrm{~B}, \mathrm{C}$ ). These results are consistent with our conclusions from SEEG: spindles are more likely to start during the transition from down to USs, whereas TBs start just before the transition to a DS. Furthermore, as with Figure $2 G$, we calculated PSDs over $500 \mathrm{~ms}$ before DS troughs, sorted DSs by power in $4-12 \mathrm{~Hz}$, took the difference of the top and bottom quartile average PSDs, and found that power is centered within theta range (Fig. 5E). Each trace is a scalp channel averaged across subjects.

\section{Relating thalamic theta with cortical theta}

Three patients also had SEEG electrodes that recorded from the thalamus and we recently characterized the coordination of NREM DS and spindles between cortex and thalamus in these patients (Mak-McCully et al., 2017). Here, we investigated whether the thalamus also exhibits similar TBs to the cortex and, if so, how they relate to cortical TBs.

Both time-frequency representations locked to DSs (Fig. 6A, example channel) and averaging the raw LFP for the top and bottom quartiles of prior DS theta power (Fig. 6B, example channel) suggested that there are similar TBs before DSs in the thalamus. These oscillations could also be seen at the level of single DSs

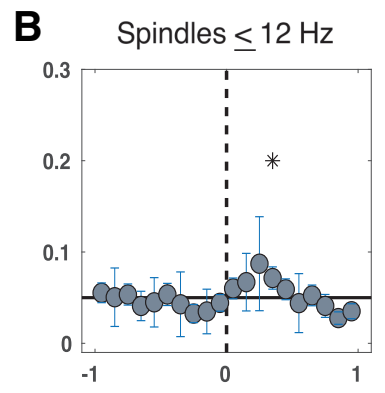

D

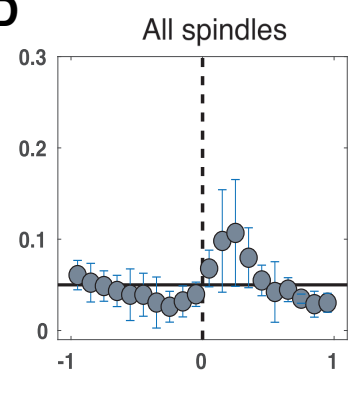

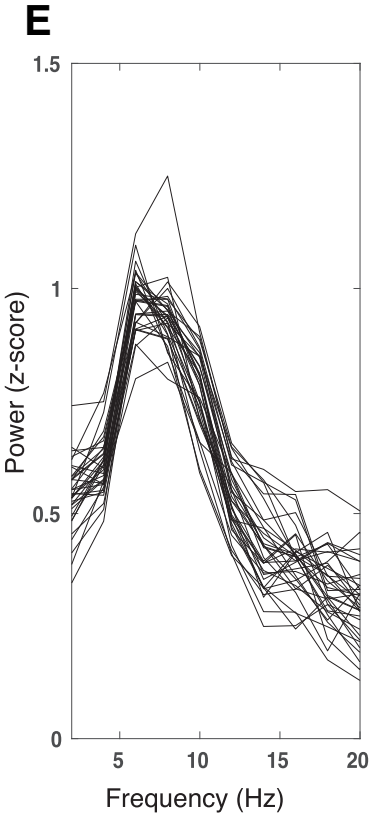

Frequency $(\mathrm{Hz})$

Figure 5. Scalp EEG theta precedes DSs and spindles follow. As in Figure 4, $\boldsymbol{E}-\boldsymbol{H}$, DS-locked event-related histograms from all per bin across channels were calculated using linear mixed-effects models. Stars indicate bins where events occur significantly the differences of the first and fourth quartile average power spectral densities of $500 \mathrm{~ms}$ pre-DS, when ranked by the amount of 4-12 Hz power they contain. Each trace represents the difference of PSDs for one channel averaged across all subjects. Only channels common to all subjects are included.

(Fig. 6B, inset) and often revealed a downward slope in the average LFP of detected TBs (Fig. 6C), similar to some cortical channels. Compared with cortical channels from the same patients (shown in Table 2), thalamic channels showed no difference in the rate of theta occurrence (mean \pm SD for thalamus $=1.07 \pm$ 0.66 ; for cortex $=1.39 \pm 0.62 ; t=1.4, p=0.16$ ), average frequency (mean $\pm \mathrm{SD}$ for thalamus $=6.25 \pm 0.13$; for cortex $=$ $6.33 \pm 0.22 ; t=1.12, p=0.26$ ), or duration (mean $\pm \mathrm{SD}$ for thalamus $=661 \pm 17 \mathrm{~ms}$; for cortex $=675 \pm 25 \mathrm{~ms} ; t=1.43, p=$ 0.15 ) in detected events. This is in contrast with DSs, which showed greater rates of occurrence in the cortex, and spindles, which occurred more frequently in the thalamus, as shown in our previous study (Mak-McCully et al., 2017).

We found that cortical TBs only slightly overlapped with thalamic TBs after correcting for the overlap expected by chance (average overlap per patient $=1.9 \%, 3.7 \%$, and $5.1 \%$ above chance), but this overlap was nonetheless significant $(t=4.04$, $p=5.3 \mathrm{e}-05$; patient as random effect, corticothalamic pair as nested random effect). In contrast, cortical spindles in most sites overlapped strongly with thalamic spindles over the proportion expected by chance (average overlap per patient $=24.2 \%, 15.6 \%$, and $26.6 \%$ above chance) and, again, this was highly significant $(t=6.22, p=5 \mathrm{e}-10$; Fig. $6 D)$. This greater corticothalamic overlap for spindles compared with TBs is significant $(t=14.2, p=$ 1.2e-45).

We also examined the cooccurrence of thalamic and cortical TBs using their joint occurrence histograms. Only 5/64 corticothalamic pairs had at least 20 thalamic TBs starting within \pm 500 ms of the start of cortical TBs, and none of these 5 pairs had histograms with a significant difference between leading versus lagging peaks as assessed with a binomial test $(p<0.05$, Bonferonni corrected). This is in contrast to spindles, which showed 
A Patient 2. Left Thalamus (Pulvinar)

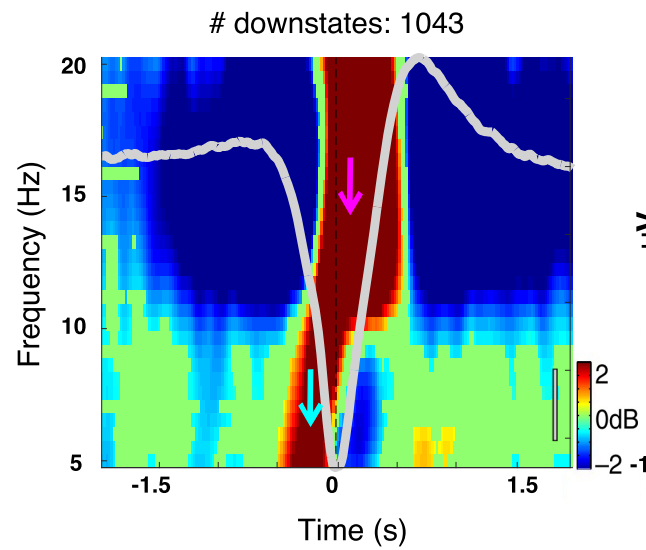

D

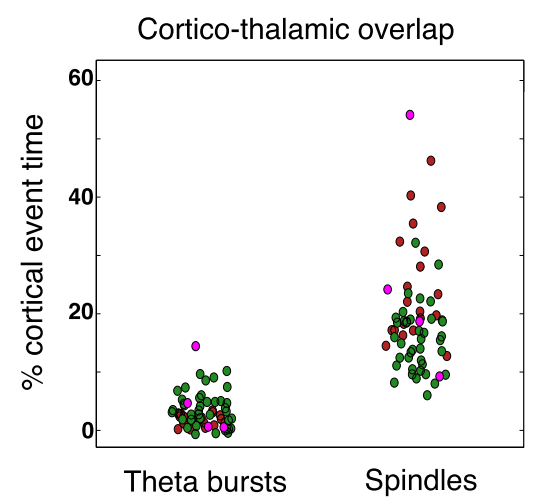

B

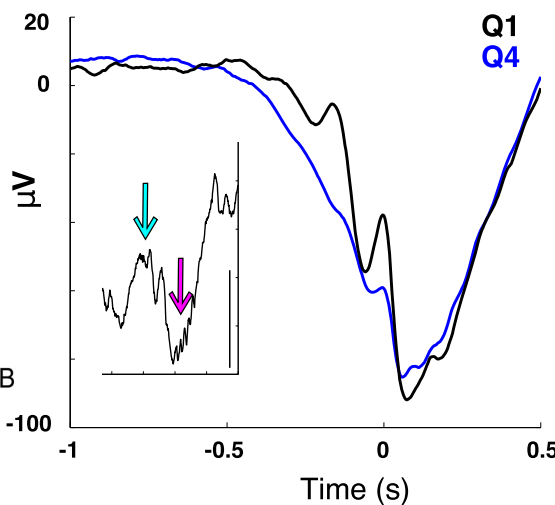

\section{C}

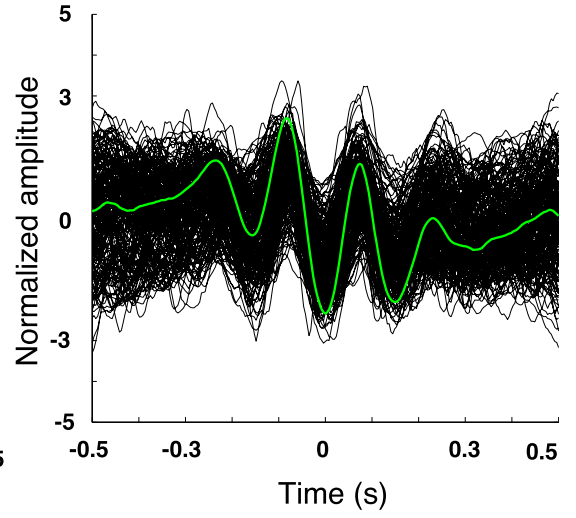

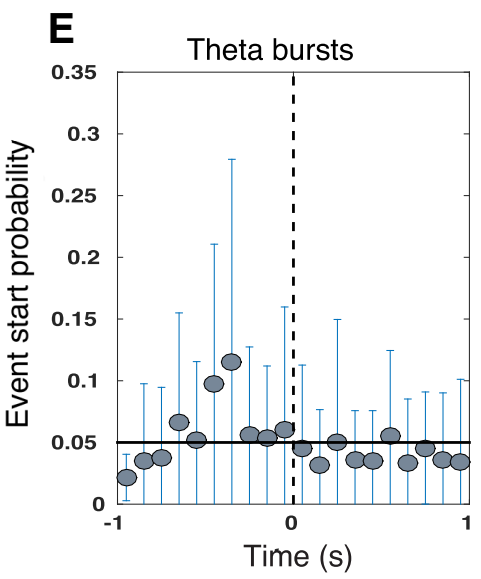

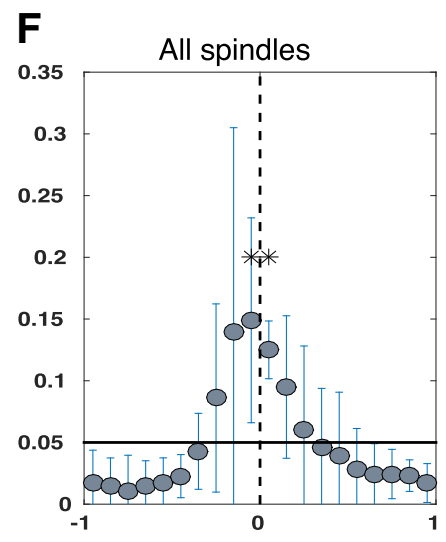

Figure 6. Thalamic theta during NREM sleep. $A$, Example time-frequency representations locked to DS troughs for a bipolar thalamic channel from Patient 2 showing increased power in the theta range before the trough (cyan arrow) and in the spindle range just after the trough (pink arrow). The average DS is overlaid in light gray. Black scale bar indicates $20 \mu \mathrm{V}$. (See Fig. 2 B in Mak-McCully et al., 2017, for time-frequency plots extending to $100 \mathrm{~Hz}$ ). B, Prior theta power is not solely driven by DS waveform shape, but displays oscillatory activity in the theta range after averaging the raw LFP locked to the first theta peak preceding the DS trough (as in Fig. $2 B, E$ ). The inset displays a single trace from the top quartile for $\pm 1 \mathrm{~s}$ around DS trough. Scale bar indicates $100 \mu \mathrm{V}$. Cyan and pink arrows show individual theta and spindle events, respectively. $\boldsymbol{C}$, All detected theta events locked to the deepest trough for the same channel as $\boldsymbol{A}$ and $\boldsymbol{B}$. $\boldsymbol{D}$, Proportion of cortical and thalamic overlap for TBs and spindles. Each dot is a different channel; dots from the same patient share the same color. $y$-axis indicates the proportion of time a given cortical channel has a TB (spindle) overlapping with a thalamic TB (spindle) after subtracting the amount of overlap expected by chance. Spindles show a greater degree of corticothalamic overlap compared with TBs $(t=14.2, p=$ 1.2e-45; patients as random effects, corticothalamic pairs as nested random effects). As in Figure 4, E-H, DS-locked event-related histograms from 8 thalamic channels, normalized by the total number of counts $\pm 1 \mathrm{~s}$ and pooled in $100 \mathrm{~ms}$ bins are plotted for the start times of: $\operatorname{TBs}(\boldsymbol{E})$ and all spindles $(\boldsymbol{F})$.

significant ordering effects with the thalamus preceding the cortex, and DSs, which usually started in the cortex before thalamus (Mak-McCully et al., 2017). These findings provide support that our detected theta events are separate entities from DSs and spindles because they appear to have distinct corticothalamic dynamics.

When relating thalamic TBs to thalamic DSs, six of eight thalamic channels from three patients had at least 20 TBs within \pm $500 \mathrm{~ms}$ of the DS trough. Of these six, two channels from two patients were more likely to have TBs start before the DS trough (binomial test, Bonferroni adjusted $p<0.05$ ); no channels were more likely to have TBs start after the trough. When pooled across patients, TBs were not more likely to start in any time bin over chance relative to DS troughs (Fig. 6E). In contrast, peak occurrence of thalamic spindle onset was at the thalamic DS peak (Fig. 6F), as has been reported previously (Mak-McCully et al., 2017).

\section{Theta and spindles differ in high-frequency coupling}

To determine whether the TBs before DSs modulated HG power, we took the top quartile of DSs with prior theta power $(5-8 \mathrm{~Hz}$,
$-500 \mathrm{~ms}$ to DS trough) and averaged both the HG $(60-100 \mathrm{~Hz})$ power and LFP locked to the band-passed theta peak first preceding the trough in the bipolar cortical channels. This revealed clear oscillations within the theta range in the HG power (Fig. $7 A$, example channel). We performed a similar analysis for spindles in the same channels, only with DSs sorted by spindle power $0-500 \mathrm{~ms}$ after DSs (Fig. $7 B$ ), and averaged time-locked to the first post-DS filtered peak in $10-16 \mathrm{~Hz}$. To quantify the extent of this modulation, we used traditional cross-frequency coupling metrics at the beginning (first two cycles) of detected spindle and TBs (see Materials and Methods).

We found that, for TBs, 42 cortical channels from 10 patients showed significant PAC-Z ( $p<0.002$, uncorrected for multiple comparisons), and 45 channels from 10 patients were significant for spindle events. There was a strong correlation between PAC-Z measures from the two event types across channels (Fig. $7 C$; Spearman's $\rho=0.59,10$ patients, 57 channels) and no difference in amplitude of PAC between theta and spindle events $(p=0.15$; $n=10,57$ channels; nested random effects of channel in patient). However, there was difference in the preferred phase for $\mathrm{HG}$ power for $\mathrm{TB}\left(\right.$ at $\sim 200^{\circ}$ ) compared with spindles (at $\sim 140^{\circ}$; Fig. 
A Patient 1. Right Middle frontal gyrus
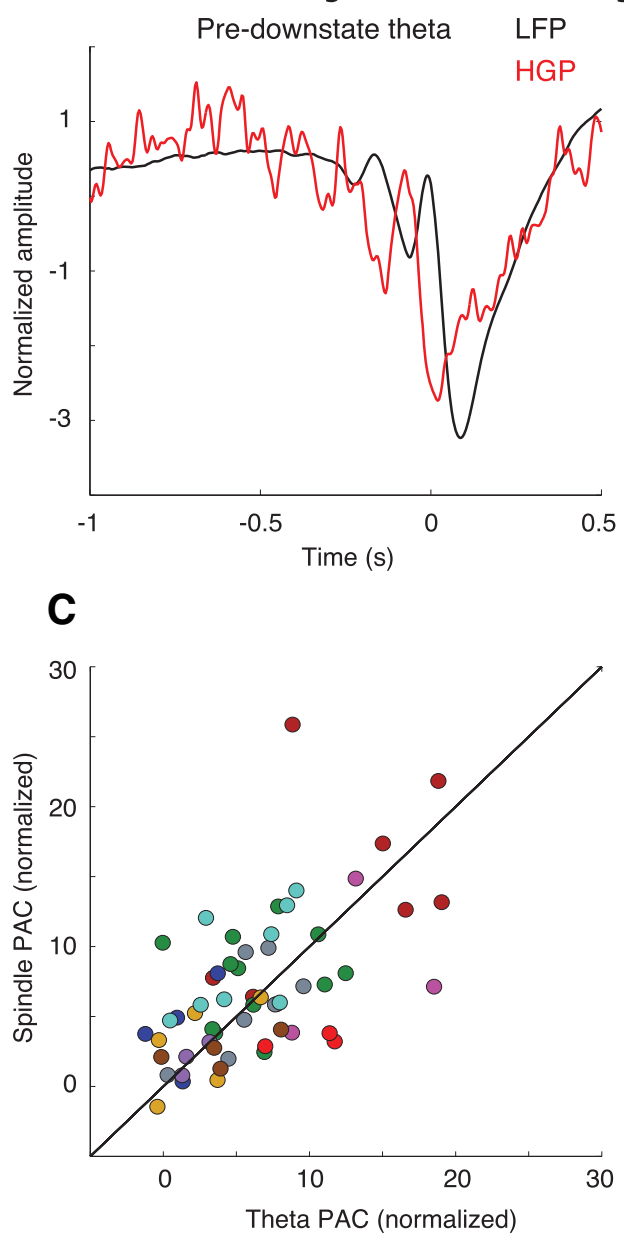

B

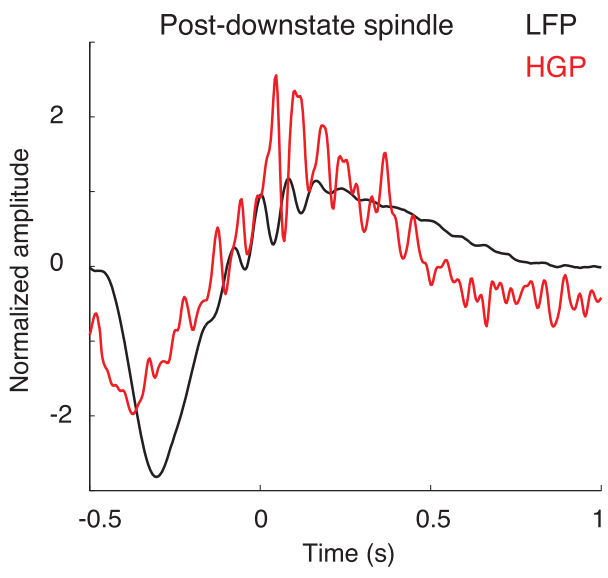

D
Preferred spindle phase
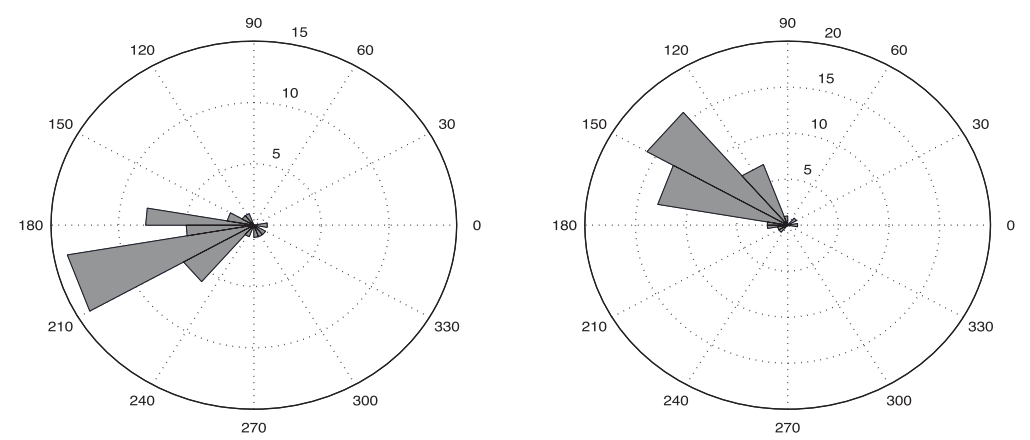

Figure 7. Theta and spindles couple to HG power differently. $A, B$, Patient 1 , right middle frontal gyrus. $A$, Average of the top quartile of DSs (ranked by pre-DS theta power) locked to the first prior theta peak (black), as well as the average of HG power $(60-100 \mathrm{~Hz})$ for the same events (red). $\boldsymbol{B}$, Average of the top quartile of DSs (ranked by post-DS spindle power) locked to the first filtered spindle peak following the DS trough (black), as well as the average of the HG power. C, Magnitude of PAC between theta phase and HG ( $x$-axis) versus spindle phase and HG ( $y$-axis) for all bipolar channels with unity line overlaid for reference. Overall, a similar level of coupling is observed for TBs versus spindles. $\boldsymbol{D}$, Preferred phase of either theta or spindle events for each channel that had significant PAC. Radial scale is number of channels. The preferred phase is consistent for each type of wave and differs significantly between TBs and spindles (parametric Watson-Williams test, $F=26.5, p=$ 1.6e-6).

7D). This difference was highly significant (parametric WatsonWilliams test, $F=26.5, p=1.6 \mathrm{e}-6)$.

\section{Discussion}

Loomis' original study recording sleep EEGs in 1939 commented on sleep spindles following KCs (i.e., DSs; Cash et al., 2009). This coupling was later quantified (Mölle et al., 2002) and then extended to assert that, whereas "fast spindles" occur after DSs, "slow spindles" occur before (Mölle et al., 2011; Klinzing et al., 2016; Yordanova et al., 2017). Like these studies, we found contrasting patterns of oscillatory activity before versus after DS. However, unlike these studies, we found that both slow and fast spindles occurred post-DS in direct cortical recordings from both frontal and occipitoparietal sites (Fig. 4), as well as scalp EEG (Fig. 5). Rather than slow spindles, we found that short TBs precede DSs whether in cortical or scalp recordings. Increased spectral power preceding DS is mainly within the theta band centered at $\sim 6 \mathrm{~Hz}$ (Figs. $2 G, 5 E$ ), but extends into the spindle range. Therefore, if this activity is band-pass filtered in the spindle range, then low-frequency "spindles" could be detected despite the center frequency of unfiltered recordings being in the theta band.
Previous scalp studies have reported increased theta power before DS troughs (Cox et al., 2014b; Klinzing et al., 2016). We confirmed that these were true oscillations by averaging the raw LFP locked to a theta peak before the DS (Fig. 2B,E) and by requiring each potential TB contain at least three peaks. TBs thus consist of multiple $4-8 \mathrm{~Hz}$ waves with a mean duration of $\sim 670$ $\mathrm{ms}$, shorter than most spindles. They have fewer cycles and lower amplitude in N3 compared with N2. The density of TB is $\sim 7$-fold less than spindles and, unlike spindles (Mak-McCully et al., 2017), TB density does not differ between cortex and thalamus. In addition, whereas spindles are tightly coupled between thalamus and cortex, no significant relationship can be observed for TB. Finally, cortical TBs have a significantly different phase relation to $\mathrm{HG}$ than spindles, indicating distinct generators (Fig. 7D). Therefore, TBs are distinguished from spindles in their internal frequency, duration, density, position relative to the DS, lack of overlap or consistent sequencing between thalamus and cortex, and distinct $\mathrm{HG}$ phase preferences.

If slow versus fast spindles do not differ in their relation to the DS, then is it still tenable to claim that they represent distinct neurophysiological phenomena rather than variations within a 
continuum? Our study confirms the slightly but significantly higher average frequency of spindles in parietal versus frontal cortex, consistent with previous EEG and MEG recordings (Dehghani et al., 2011) and intracranial recordings (Andrillon et al., 2011; Peter-Derex et al., 2012; Piantoni et al., 2017). The individual waves in EEG and MEG spindle bursts also vary in frequency, with later waves also $\sim 1 \mathrm{~Hz}$ slower on average (Dehghani et al., 2011). In SEEG, within a given cortical location and often within the same spindle, spindle waves with frequencies both above and below the fast/slow division are typically observed. Two kinds of spindles can be identified in laminar recordings, involving mainly upper or middle layers (Hagler et al., 2018). The average frequency of upper versus middle channel spindles does not differ significantly and both include both slow and fast spindle waves. In all of these circumstances, fast and slow spindles occur in a continuum rather than a dichotomy.

Within this framework, it is not clear how to explain how, in some subjects, two peaks in the spindle spectrogram can be discerned at the scalp (Cox et al., 2017). The cortical origin of scalp EEG spindles is not yet well understood due to the lack of detailed information regarding the amplitude, density, synchrony, phase, and orientation of the generating cortical patches. It is thus theoretically possible that the slower spindles reported at the scalp are from a location where we did not record. However, the parietal and frontal cortices where we recorded have been proposed to be the generators of fast and slow scalp spindles (Mölle et al., 2011; Klinzing et al., 2016) and generate spindle band activity most related to scalp EEG spindles (Frauscher et al., 2015). Because the inverse problem is ill posed, it is possible to model the scalp EEG spindle distribution as being due to either anatomically distinct generators, each with a single frequency, or distributed generators, each with a range of overlapping frequencies, changing slightly across areas. Our results clearly support the second model.

This supposed dichotomy between slow pre-DS spindles and fast post-DS spindles in humans has been homologized to the clear dichotomy in rodents between high-voltage slow spindles $(\sim 8 \mathrm{~Hz})$ versus low-voltage fast spindles $(\sim 14 \mathrm{~Hz})$ (Timofeev and Chauvette, 2013). Only the fast spindles are associated with memory replay and consolidation (Eschenko et al., 2006; Johnson et al., 2010) or DS (Johnson et al., 2010). The sharp waveforms and other epileptiform characteristics of slow rodent spindles (Polack and Charpier, 2006) suggest that they do not have an homology in healthy human recordings. Therefore, it appears that fast rodent spindles correspond to both faster and slower spindles in humans.

The TBs preceding DS in N2 comprise an augmenting oscillation between cortical excitation and inhibition as indexed by phase-locked HG, which is correlated with neuronal firing (Lachaux et al., 2012). The greatest HG decrease occurs at the final surface-negative TB trough, which coincides with the DS trough. Therefore, in TB-DS sequences, the DS does not arise as a sudden decline from baseline, but as the culmination of an escalating TB oscillation, suggesting that the TB may play a role in helping to trigger the DS as its final cycle. This possibility receives some indirect support from the fact that they are generated by the same cortical layers in laminar recordings (Csercsa et al., 2010; Halgren et al., 2018) and thus may be engaging the same circuits. The hypothesis that theta waves may trigger DS in N2 provides a solution to a difficult question: how do KCs arise? Current theories model DS onset as a response to the preceding US (Neske, 2015). This view describes the usual in vitro or anesthetized recordings where USs arise from a flat depressed baseline, which is considered the DS (Lemieux et al., 2014). In contrast, in unanesthetized humans (Mak-McCully et al., 2015) and animals (Chauvette et al., 2011), DS appear as stereotyped events in a chronically active cortex during NREM sleep. Laminar recordings in humans demonstrate that KCs are DS without a preceding US (Cash et al., 2009). We suggest here that the last positive peak of the TB may replace the US as the DS trigger. For example, the calcium influx associated with this cortical excitation during the final positive peak would trigger hyperpolarizing $\mathrm{K}^{+}$currents (Cunningham et al., 2006), which may tip the circuit into the DS. However, although TBs could serve as a trigger for DSs in N2, the majority of DSs are not preceded by TBs, so this triggering phenomenon may only occur in some circumstances.

The consistent relation of TB to DS and DS to spindles may be related to the appearance of these waves in successive stages of sleep. The transition from quiet waking to $\mathrm{N} 1$ is marked by the replacement of alpha by theta waves. N2 then appears when KCs and sleep spindles appear. Simultaneous corticothalamic recordings in natural human sleep show that converging cortical DS precede thalamic DS, that thalamic spindles are tightly coupled to begin at the thalamic DS trough, and that thalamic spindles drive cortical (Mak-McCully et al., 2017). In this view, the N1 to N2 transition would occur when theta begins to trigger cortical DSs (i.e., KCs), which in turn trigger successively thalamic DS, thalamic spindles, and cortical spindles. $\mathrm{N} 2$ transitions to $\mathrm{N} 3$ when DS and US recur rhythmically as the slow oscillation. Both TBs (shown here) and spindles (Andrillon et al., 2011; Mak-McCully et al., 2017; Piantoni et al., 2017) continue during N3, but become abbreviated. We hypothesize that, as the neuromodulatory state deepens, the US triggered by the DS becomes capable of triggering the following DS, resulting in less time for elaboration of the TB or spindles.

During NREM sleep, hippocampal cells replay events from the preceding waking period during sharp-wave ripples, which arrive at the cortex during the down to US transition, as the spindle is beginning (Maingret et al., 2016; Jiang et al., 2017). This conjunction of hippocampal input with cortical modulation is thought to underlie consolidation of cortical memory circuits (Diekelmann and Born, 2010; Mölle et al., 2011; Niknazar et al., 2015; Hanert et al., 2017; Latchoumane et al., 2017). Our results suggest that TBs may precede and could help to initiate the DSripple-spindle-US sequence. During waking, theta occurs during tasks requiring sustained processing (Kahana et al., 1999; Raghavachari et al., 2006) and may underlie prominent cognitive eventrelated potentials (Cavanagh et al., 2012; Halgren et al., 2015). If theta serves a similar function during NREM, then TB may organize the gathering of cortical information before the DS and consequently help to select related hippocampal traces to be activated and sent back to the cortex for integration with currently active neurons during the US and spindle.

\section{References}

Andrillon T, Nir Y, Staba RJ, Ferrarelli F, Cirelli C, Tononi G, Fried I (2011) Sleep spindles in humans: insights from intracranial EEG and unit recordings. J Neurosci 31:17821-17834. CrossRef Medline

Barthó P, Slézia A, Mátyás F, Faradzs-Zade L, Ulbert I, Harris KD, Acsády L (2014) Ongoing network state controls the length of sleep spindles via inhibitory activity. Neuron 82:1367-1379. CrossRef Medline

Bazhenov M, Timofeev I, Steriade M, Sejnowski TJ (2002) Model of thalamocortical slow-wave sleep oscillations and transitions to activated states. J Neurosci 22:8691-8704. CrossRef Medline

Bonjean M, Baker T, Lemieux M, Timofeev I, Sejnowski T, Bazhenov M (2011) Corticothalamic feedback controls sleep spindle duration in vivo. J Neurosci 31:9124-9134. CrossRef Medline

Canolty RT, Edwards E, Dalal SS, Soltani M, Nagarajan SS, Kirsch HE, Berger 
MS, Barbaro NM, Knight RT (2006) High gamma power is phaselocked to theta oscillations in human neocortex. Science 313:1626-1628. CrossRef Medline

Cash SS, Halgren E, Dehghani N, Rossetti AO, Thesen T, Wang C, Devinsky O, Kuzniecky R, Doyle W, Madsen JR, Bromfield E, Eross L, Halász P, Karmos G, Csercsa R, Wittner L, Ulbert I (2009) The human K-complex represents an isolated cortical down-state. Science 324:1084-1087. CrossRef Medline

Cavanagh JF, Zambrano-Vazquez L, Allen JJ (2012) Theta lingua franca: A common mid-frontal substrate for action monitoring processes. Psychophysiology 49:220-238. CrossRef Medline

Chauvette S, Crochet S, Volgushev M, Timofeev I (2011) Properties of slow oscillation during slow-wave sleep and anesthesia in cats. J Neurosci 31: 14998-15008. CrossRef Medline

Contreras D, Destexhe A, Sejnowski TJ, Steriade M (1996) Control of spatiotemporal coherence of a thalamic oscillation by corticothalamic feedback. Science 274:771-774. CrossRef Medline

Cox R, Hofman WF, de Boer M, Talamini LM (2014a) Local sleep spindle modulations in relation to specific memory cues. Neuroimage 99:103110. CrossRef Medline

Cox R, van Driel J, de Boer M, Talamini LM (2014b) Slow oscillations during sleep coordinate interregional communication in cortical networks. J Neurosci 34:16890-16901. CrossRef Medline

Cox R, Schapiro AC, Manoach DS, Stickgold R (2017) Individual differences in frequency and topography of slow and fast sleep spindles. Front Hum Neurosci 11:433. CrossRef Medline

Crunelli V, Hughes SW (2010) The slow (below $1 \mathrm{~Hz}$ ) rhythm of non-REM sleep: a dialogue between three cardinal oscillators. Nat Neurosci 13:917. CrossRef Medline

Csercsa R, Dombovári B, Fabó D, Wittner L, Eross L, Entz L, Sólyom A, Rásonyi G, Szucs A, Kelemen A, Jakus R, Juhos V, Grand L, Magony A, Halász P, Freund TF, Maglóczky Z, Cash SS, Papp L, Karmos G et al. (2010) Laminar analysis of slow wave activity in humans. Brain 133: 2814-2829. CrossRef Medline

Cunningham MO, Pervouchine DD, Racca C, Kopell NJ, Davies CH, Jones RS, Traub RD, Whittington MA (2006) Neuronal metabolism governs cortical network response state. Proc Natl Acad Sci U S A 103:5597-5601. CrossRef Medline

Dehghani N, Cash SS, Halgren E (2011) Topographical frequency dynamics within EEG and MEG sleep spindles. Clin Neurophysiol 122:229-235. CrossRef Medline

Delorme A, Makeig S (2004) EEGLAB: an open source toolbox for analysis of single-trial EEG dynamics including independent component analysis. J Neurosci Methods 134:9-21. CrossRef Medline

Diekelmann S, Born J (2010) The memory function of sleep. Nat Rev Neurosci 11:114-126. CrossRef Medline

Duvernoy H (1999) The human brain: surface, blood supply, and threedimensional sectional anatomy, Ed 22. New York: Springer.

Dykstra AR, Chan AM, Quinn BT, Zepeda R, Keller CJ, Cormier J, Madsen JR, Eskandar EN, Cash SS (2012) Individualized localization and cortical surface-based registration of intracranial electrodes. Neuroimage 59: 3563-3570. CrossRef Medline

Eschenko O, Mölle M, Born J, Sara SJ (2006) Elevated sleep spindle density after learning or after retrieval in rats. J Neurosci 26:12914-12920. CrossRef Medline

Fogerson PM, Huguenard JR (2016) Tapping the brakes: cellular and synaptic mechanisms that regulate thalamic oscillations. Neuron 92:687704. CrossRef Medline

Frauscher B, von Ellenrieder N, Dubeau F, Gotman J (2015) Scalp spindles are associated with widespread intracranial activity with unexpectedly low synchrony. Neuroimage 105:1-12. CrossRef Medline

Hagler DJ Jr, Ulbert I, Wittner L, Erőss L, Madsen JR, Devinsky O, Doyle W, Fabó D, Cash SS, Halgren E (2018) Heterogeneous origins of human sleep spindles in different cortical layers. J Neurosci 38:3013-3025. CrossRef Medline

Halgren E, Kaestner E, Marinkovic K, Cash SS, Wang C, Schomer DL, Madsen JR, Ulbert I (2015) Laminar profile of spontaneous and evoked theta: rhythmic modulation of cortical processing during word integration. Neuropsychologia 76:108-124. CrossRef Medline

Halgren M, Fabó D, Ulbert I, Madsen JR, Erőss L, Doyle WK, Devinsky O, Schomer D, Cash SS, Halgren E (2018) Superficial slow rhythms integrate cortical processing in humans. Sci Rep 8:2055. CrossRef Medline
Hanert A, Weber FD, Pedersen A, Born J, Bartsch T (2017) Sleep in humans stabilizes pattern separation performance. J Neurosci 37:12238-12246. CrossRef Medline

Iber C, Ancoli-Israel S, Chesson AL, Quan SF (2007) The AASM manual for the scoring of sleep and associated events: rules, terminology, and technical specifications, Ed 1. Westchester, IL: American Academy of Sleep Medicine.

Jiang X, Shamie I, K Doyle W, Friedman D, Dugan P, Devinsky O, Eskandar E, Cash SS, Thesen T, Halgren E (2017) Replay of large-scale spatiotemporal patterns from waking during subsequent NREM sleep in human cortex. Sci Rep 7:17380. CrossRef Medline

Johnson LA, Euston DR, Tatsuno M, McNaughton BL (2010) Stored-trace reactivation in rat prefrontal cortex is correlated with down-to-up state fluctuation density. J Neurosci 30:2650-2661. CrossRef Medline

Jones SR (2016) When brain rhythms aren't "rhythmic": implication for their mechanisms and meaning. Curr Opin Neurobiol 40:72-80. CrossRef Medline

Kahana MJ, Sekuler R, Caplan JB, Kirschen M, Madsen JR (1999) Human theta oscillations exhibit task dependence during virtual maze navigation. Nature 399:781-784. CrossRef Medline

Klinzing JG, Mölle M, Weber F, Supp G, Hipp JF, Engel AK, Born J (2016) Spindle activity phase-locked to sleep slow oscillations. Neuroimage 134: 607-616. CrossRef Medline

Kokkinos V, Kostopoulos GK (2011) Human non-rapid eye movement stage II sleep spindles are blocked upon spontaneous K-complex coincidence and resume as higher frequency spindles afterwards. J Sleep Res 20:57-72. CrossRef Medline

Kokkinos V, Koupparis AM, Kostopoulos GK (2013) An intra-K-complex oscillation with independent and labile frequency and topography in NREM sleep. Front Hum Neurosci 7:163. CrossRef Medline

Lachaux JP, Axmacher N, Mormann F, Halgren E, Crone NE (2012) Highfrequency neural activity and human cognition: past, present and possible future of intracranial EEG research. Prog Neurobiol 98:279-301. CrossRef Medline

Latchoumane CV, Ngo HV, Born J, Shin HS (2017) Thalamic spindles promote memory formation during sleep through triple phase-locking of cortical, thalamic, and hippocampal rhythms. Neuron 95:424-435.e6. CrossRef Medline

Lemieux M, Chen JY, Lonjers P, Bazhenov M, Timofeev I (2014) The impact of cortical deafferentation on the neocortical slow oscillation. J Neurosci 34:5689-5703. CrossRef Medline

Maingret N, Girardeau G, Todorova R, Goutierre M, Zugaro M (2016) Hippocampo-cortical coupling mediates memory consolidation during sleep. Nat Neurosci 19:959-964. CrossRef Medline

Mak-McCully RA, Rolland M, Sargsyan A, Gonzalez C, Magnin M, Chauvel P, Rey M, Bastuji H, Halgren E (2017) Coordination of cortical and thalamic activity during non-REM sleep in humans. Nat Commun 8:15499. CrossRef Medline

Mak-McCully RA, Rosen BQ, Rolland M, Régis J, Bartolomei F, Rey M, Chauvel P, Cash SS, Halgren E (2015) Distribution, amplitude, incidence, co-occurrence, and propagation of human k-complexes in focal transcortical recordings. eNeuro 2:ENEURO.0028-15.2015. CrossRef Medline

Mölle M, Bergmann TO, Marshall L, Born J (2011) Fast and slow spindles during the sleep slow oscillation: disparate coalescence and engagement in memory processing. Sleep 34:1411-1421. CrossRef Medline

Mölle M, Marshall L, Gais S, Born J (2002) Grouping of spindle activity during slow oscillations in human non-rapid eye movement sleep. J Neurosci 22:10941-10947. CrossRef Medline

Morel A, Magnin M, Jeanmonod D (1997) Multiarchitectonic and stereotactic atlas of the human thalamus. J Comp Neurol 387:588-630. CrossRef Medline

Neske GT (2015) The slow oscillation in cortical and thalamic networks: mechanisms and functions. Front Neural Circuits 9:88. CrossRef Medline

Niknazar M, Krishnan GP, Bazhenov M, Mednick SC (2015) Coupling of thalamocortical sleep oscillations are important for memory consolidation in humans. PLoS One 10:e0144720. CrossRef Medline

Peter-Derex L, Comte JC, Mauguière F, Salin PA (2012) Density and frequency caudo-rostral gradients of sleep spindles recorded in the human cortex. Sleep 35:69-79. CrossRef Medline 
Piantoni G, Halgren E, Cash SS (2017) Spatiotemporal characteristics of sleep spindles depend on cortical location. Neuroimage 146:236-245. CrossRef Medline

Polack PO, Charpier S (2006) Intracellular activity of cortical and thalamic neurones during high-voltage rhythmic spike discharge in Long-Evans rats in vivo. J Physiol 571:461-476. CrossRef Medline

Raghavachari S, Lisman JE, Tully M, Madsen JR, Bromfield EB, Kahana MJ (2006) Theta oscillations in human cortex during a working-memory task: evidence for local generators. J Neurophysiol 95:1630-1638. CrossRef Medline

Rodenbeck, A. et al., (2006) A review of sleep EEG patterns. part I: aAcompilation of amended rules for their visual recognition according to Rechtschaffen and Kales. Somnologie 10:159-175. CrossRef

Sejnowski TJ, Destexhe A (2000) Why do we sleep? Brain Res 886:208-223. CrossRef Medline

Silber MH, Ancoli-Israel S, Bonnet MH, Chokroverty S, Grigg-Damberger MM, Hirshkowitz M, Kapen S, Keenan SA, Kryger MH, Penzel T, Press- man MR, Iber C (2007) The visual scoring of sleep in adults. J Clin Sleep Med 3:121-131. Medline

Steriade M (1997) Synchronized activities of coupled oscillators in the cerebral cortex and thalamus at different levels of vigilance. Cereb Cortex 7:583-604. CrossRef Medline

Talairach J, Tournoux P (1998) Co-planar stereotaxic atlas of the human brain: 3-dimensional proportional system: an approach to cerebral imaging. New York, NY: Thieme.

Timofeev I, Chauvette S (2013) The spindles: are they still thalamic? Sleep 36:825-826. CrossRef Medline

Timofeev I, Grenier F, Bazhenov M, Sejnowski TJ, Steriade M (2000) Origin of slow cortical oscillations in deafferented cortical slabs. Cereb Cortex 10:1185-1199. CrossRef Medline

Yordanova J, Kirov R, Verleger R, Kolev V (2017) Dynamic coupling between slow waves and sleep spindles during slow wave sleep in humans is modulated by functional pre-sleep activation. Scientific Reports, 7, pp. 1-14. 